\title{
Curriculum for optical diagnosis training in Europe: European Society of Gastrointestinal Endoscopy (ESGE) Position Statement
}

\section{(द) \\ ESGE}

Authors

Evelien Dekker ${ }^{1^{*}}$, Britt B. S. L. Houwen ${ }^{1^{*}}$, Ignasi Puig ${ }^{2,3}$, Marco Bustamante-Balén ${ }^{4,5}$, Emmanuel Coron ${ }^{6}$, Daniela E. Dobru $^{7}$, Roman Kuvaev ${ }^{8,9}$, Helmut Neumann ${ }^{10}$, Gavin Johnson ${ }^{11}$, Pedro Pimentel-Nunes ${ }^{12,13,14}$, David S. Sanders ${ }^{15}$, Mario Dinis-Ribeiro ${ }^{12,13}$, Marianna Arvanitakis ${ }^{16}$, Thierry Ponchon ${ }^{17}$, James E. East ${ }^{18,19}$, Raf Bisschops ${ }^{20}$

Institutions

1 Department of Gastroenterology and Hepatology, Amsterdam University Medical Centre, location Academic Medical Centre, University of Amsterdam, Amsterdam, The Netherlands

2 Digestive Diseases Department, Althaia Xarxa Assistencial Universitària de Manresa, Manresa, Spain

3 Department of Medicine, Facultat de Ciències de la Salut, Universitat de Vic-Universitat Central de Catalunya (UVic-UCC), Manresa, Spain

4 Gastrointestinal Endoscopy Unit, Digestive Diseases Department, La Fe Polytechnic University Hospital, Valencia, Spain

5 Gastrointestinal Endoscopy Research Group, La Fe Health Research Institute, Valencia, Spain

6 Institut des Maladies de l'Appareil Digestif (IMAD), CHU Nantes, Université Nantes, Nantes, France

7 Gastroenterology Department, County Hospital Mures, Targu Mures, Romania

8 Endoscopy Department, Yaroslavl Regional Cancer Hospital, Yaroslavl, Russian Federation

9 Department of Gastroenterology, Faculty of Additional Professional Education, Pirogov Russian National Research Medical University, Moscow, Russian Federation

10 Department of Medicine I, University Medical Center Mainz, Mainz, Germany

11 Department of Gastroenterology, University College London Hospitals, London, UK

12 Gastroenterology Department, Portuguese Oncology Institute of Porto, Porto, Portugal

13 Center for Research in Health Technologies and Information Systems (CINTESIS), Faculty of Medicine, University of Porto, Porto, Portugal

14 Surgery and Physiology Department, Faculty of Medicine of the University of Porto, Porto, Portugal

15 Academic Unit of Gastroenterology, Royal Hallamshire Hospital, Sheffield, UK
16 Department of Gastroenterology, Hepatopancreatology and Digestive Oncology, Erasme University Hospital, Brussels, Belgium

17 Gastroenterology Division, Hôpital Edouard Herriot, Lyon, France

18 Translational Gastroenterology Unit, Nuffield Department of Medicine, Experimental Medicine Division, John Radcliffe Hospital, University of Oxford, Oxford, UK

19 Oxford National Institute for Health Research Biomedical Research Centre, University of Oxford, Oxford, UK

20 Department of Gastroenterology and Hepatology, Catholic University of Leuven (KUL), TARGID, University Hospital Leuven, Leuven, Belgium

published online $\quad 3.9 .2020$

\section{Bibliography}

Endoscopy 2020; 52: 899-923

DOI 10.1055/a-1231-5123

ISSN 0013-726X

(c) 2020. Thieme. All rights reserved. Georg Thieme Verlag KG, Rüdigerstraße 14, 70469 Stuttgart, Germany

丹upplementary material Online content viewable at: https://doi.org/10.1055/a-1231-5123

Additional online content available on the ESGE website at: https://www.esge.com/optical-diagnosis-training-curriculum/

\section{Corresponding author}

Evelien Dekker, MD PhD, Department of Gastroenterology and Hepatology, Amsterdam University Medical Centre, location Academic Medical Centre, University of Amsterdam, Meibergdreef 9, 1105 AZ Amsterdam,

The Netherlands

Fax: +31-20-6917033

e.dekker@amsterdamumc.nl 


\section{MAIN RECOMMENDATIONS}

This manuscript represents an official Position Statement of the European Society of Gastrointestinal Endoscopy (ESGE) aiming to guide general gastroenterologists to develop and maintain skills in optical diagnosis during endoscopy. In general, this requires additional training beyond the core curriculum currently provided in each country. In this context, ESGE have developed a European core curriculum for optical diagnosis practice across Europe for high quality optical diagnosis training.

1 ESGE suggests that every endoscopist should have achieved general competence in upper and/or lower gastrointestinal (UGI/LGI) endoscopy before commencing training in optical diagnosis of the UGI/LGI tract, meaning personal experience of at least $300 \mathrm{UGI}$ and/or 300 LGI endoscopies and meeting the ESGE quality measures for UGI/ LGI endoscopy. ESGE suggests that every endoscopist should be able and competent to perform UGI/LGI endoscopy with high definition white light combined with virtual and/or dye-based chromoendoscopy before commencing training in optical diagnosis.
2 ESGE suggests competency in optical diagnosis can be learned by attending a validated optical diagnosis training course based on a validated classification, and self-learning with a minimum number of lesions. If no validated training course is available, optical diagnosis can only be learned by attending a non-validated onsite training course and selflearning with a minimum number of lesions.

3 ESGE suggests endoscopists are competent in optical diagnosis after meeting the pre-adoption and learning criteria, and meeting competence thresholds by assessing a minimum number of lesions prospectively during realtime endoscopy. ESGE suggests ongoing in vivo practice by endoscopists to maintain competence in optical diagnosis. If a competent endoscopist does not perform in vivo optical diagnosis on a regular basis, ESGE suggests repeating the learning and competence phases to maintain competence.

Key areas of interest were optical diagnosis training in Barrett's esophagus, esophageal squamous cell carcinoma, early gastric cancer, diminutive colorectal lesions, early colorectal cancer, and neoplasia in inflammatory bowel disease. Condition-specific recommendations are provided in the main document.

\section{SOURCE AND SCOPE}

This position statement is an official statement of the European Society of Gastrointestinal Endoscopy (ESGE). It provides recommendations for a European core curriculum aimed at providing high quality training in optical diagnosis. The recommendations presented are based on a consensus among endoscopists considered to be experts in optical diagnosis who are involved in optical diagnosis training and training courses in Europe.

\section{Introduction}

Real-time optical diagnosis emerged more than 40 years ago, with the application of dyes such as indigo carmine and methylene blue during endoscopic examination, and further developed with the introduction of high definition imaging, optical magnification, and virtual chromoendoscopy. All these developments allow detailed inspection of the digestive mucosa, visualizing the mucosal pattern and enhancing the microvasculature, which are of pivotal importance in characterizing carcinogenesis and inflammation.

Optical diagnosis during endoscopy is an important skill for predicting histology to guide optimal treatment and surveillance decisions. Choosing the appropriate treatment method should balance under- and overtreatment of patients and reduce treatment-related costs. Furthermore, recent studies have demonstrated that implementing an optical diagnosis strategy for diminutive colorectal lesions could reduce the

$\begin{array}{ll}\text { ABBREVIATIONS } \\ \text { ASGE } & \text { American Society of Gastrointestinal Endoscopy } \\ \text { AUC } & \text { area under the curve } \\ \text { BE } & \text { Barrett's esophagus } \\ \text { BLI } & \text { blue light imaging } \\ \text { BORN } & \text { Barrett's esophagus-related neoplasia } \\ \text { CRC } & \text { colorectal cancer } \\ \text { EGC } & \text { early gastric cancer } \\ \text { EMR } & \text { endoscopic mucosal resection } \\ \text { ESCC } & \text { esophageal squamous cell carcinoma } \\ \text { ESD } & \text { endoscopic submucosal dissection } \\ \text { ESGE } & \text { European Society of Gastrointestinal Endoscopy } \\ \text { FICE } & \text { Flexible Spectral Imaging Color Enhancement } \\ \text { GI } & \text { gastrointestinal } \\ \text { GRADE } & \text { Grading of Recommendations Assessment, } \\ & \text { Development and Evaluation } \\ \text { IBD } & \text { inflammatory bowel disease } \\ \text { JES } & \text { Japan Esophageal Society } \\ \text { JNET } & \text { Japanese NBI Expert Team } \\ \text { LGI } & \text { lower gastrointestinal } \\ \text { NBI } & \text { narrow-band imaging } \\ \text { NICE } & \text { NBI International Colorectal Endoscopic } \\ \text { NPV } & \text { negative predictive value } \\ \text { PIVI } & \text { Preservation and Incorporation of Valuable } \\ & \text { Endoscopic Innovations } \\ \text { UGI } & \text { upper gastrointestinal } \\ \text { VS } & \text { vessel plus surface classification } \\ \text { WASP } & \text { Workgroup on serrAted polypS and Polyposis } \\ \text { WLE } & \text { white-light endoscopy } \\ & \end{array}$


colonoscopy-associated costs for histopathology and polypectomy substantially, besides reducing patient burden [1 -3$]$.

In expert hands, optical diagnosis has been demonstrated to be very helpful in predicting the histology of various disorders, including diminutive colorectal lesions, early colorectal cancer (CRC), early gastric cancer (EGC), esophageal squamous cell carcinoma (ESCC), and Barrett's esophagus (BE). However, the performance of optical diagnosis by endoscopists varies greatly and depends on training, experience, and equipment [4-9]. At the moment, standardized training courses based on validated classification systems, aiming to reach and maintain optical diagnosis skills for endoscopists, are very rare. The available training courses demonstrate a huge variability in their content, the endoscopy system, and the setting of the training. Training is generally done by classroom teaching or computer-based training, and may consist of images, videos, or real-time endoscopies. Endoscopists attending such courses may have varying experience and access to different types of endoscopic equipment and enhanced imaging techniques, with or without magnification. Optimization of the current practice of optical diagnosis and concurrent training curricula are therefore warranted.

The recommendations presented in this curriculum ( $\bullet$ Table 1 and $\downarrow$ Table 2 ) are based on a consensus among optical diagnosis experts who are involved in optical diagnosis training.

\section{Aims}

The aim of this Position Statement is to establish practical guidance to optimize optical diagnosis training in Europe, based on the currently published evidence and knowledge. This manuscript focuses on training and aims to help gastroenterologists in general practice to develop and maintain skills in optical diagnosis during endoscopy ( $\triangleright$ Fig. 1 ). Specifically, it was not intended for it to look at accreditation or practice standards, which are the remit of advanced imaging guidelines.

\section{Methods}

This curriculum was developed through a Delphi consensus method among European experts in optical diagnosis [10]. As chair of the European Society of Gastrointestinal Endoscopy (ESGE) curricula working group [11], R.B. invited E.D. and J.E. to be the section chairs for the optical diagnosis training curriculum. After a call for participants in July 2017, R.B., E.D., and J.E. selected the members, based on curriculum, optical diagnosis experience, publications, and motivation, in December 2017. During a face-to-face meeting in February 2018, all members were introduced to the methodology, and subtopics for optical diagnosis training were selected: BE, ESCC, EGC, diminutive colorectal lesions, early CRC, and inflammatory bowel disease (IBD). The term "optical diagnosis" in this curriculum relates exclusively to the differentiation between non-neoplastic lesions and neoplastic lesions, and the prediction of (invasive) cancer within a neoplastic lesion. Taskforces for the six subtopics were formed (Appendix 1s; see online-only Supplementary material).

- Table 1 Summary of the ESGE training curriculum recommendations for optical diagnosis in general.

\section{A. Pre-adoption requirements to start optical diagnosis training}

Personal experience of at least $300 \mathrm{UGl}$ and/or 300 LGI endoscopies

Meeting the ESGE key quality performance measures for UGI and/or LGI endoscopy

Being able and competent to perform UGI/LGI endoscopy with high definition white-light endoscopy combined with virtual and/or dye-based chromoendoscopy

B. Training/learning steps optical diagnosis

Attending a validated training course based on a validated classification (including an in vivo part)/ Attending an onsite training course of 1 week's duration with an expert (including training on techniques and any validated classification)

Self-learning by assessing a minimum number of lesions with histopathology as the reference

C. Assessment criteria for optical diagnosis proficiency

Being competent in optical diagnosis
Meeting pre-adoption requirements and training/ learning steps for optical diagnosis

Meeting competence thresholds by assessing a minimum number of lesions prospectively during real-time endoscopy with histopathology as the reference (if not incorporated in training)

Maintaining Ongoing in vivo practice

competence in optical diagnosis
UGI, upper gastrointestinal; LGI, lower gastrointestinal.

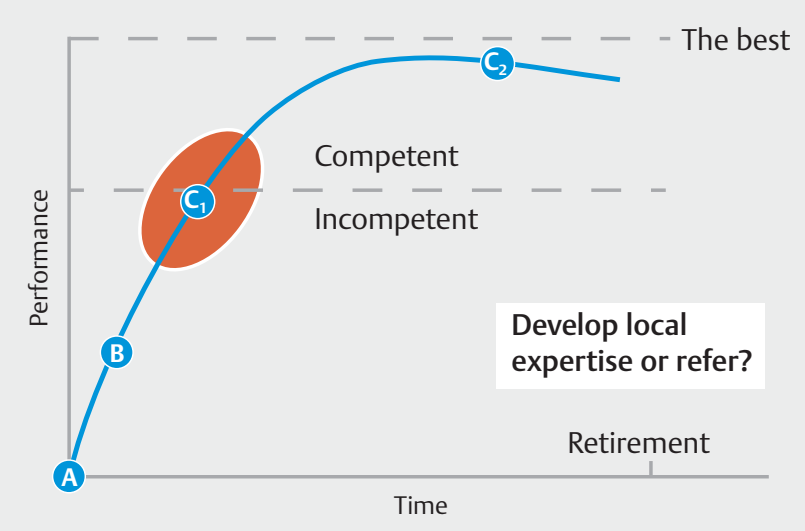

- Fig. 1 A summary of the optical diagnosis training performance principles. A, pre-adoption requirements; $B$, training/learning steps; $C_{1}$, achieving competence; $C_{2}$, maintaining competence. 


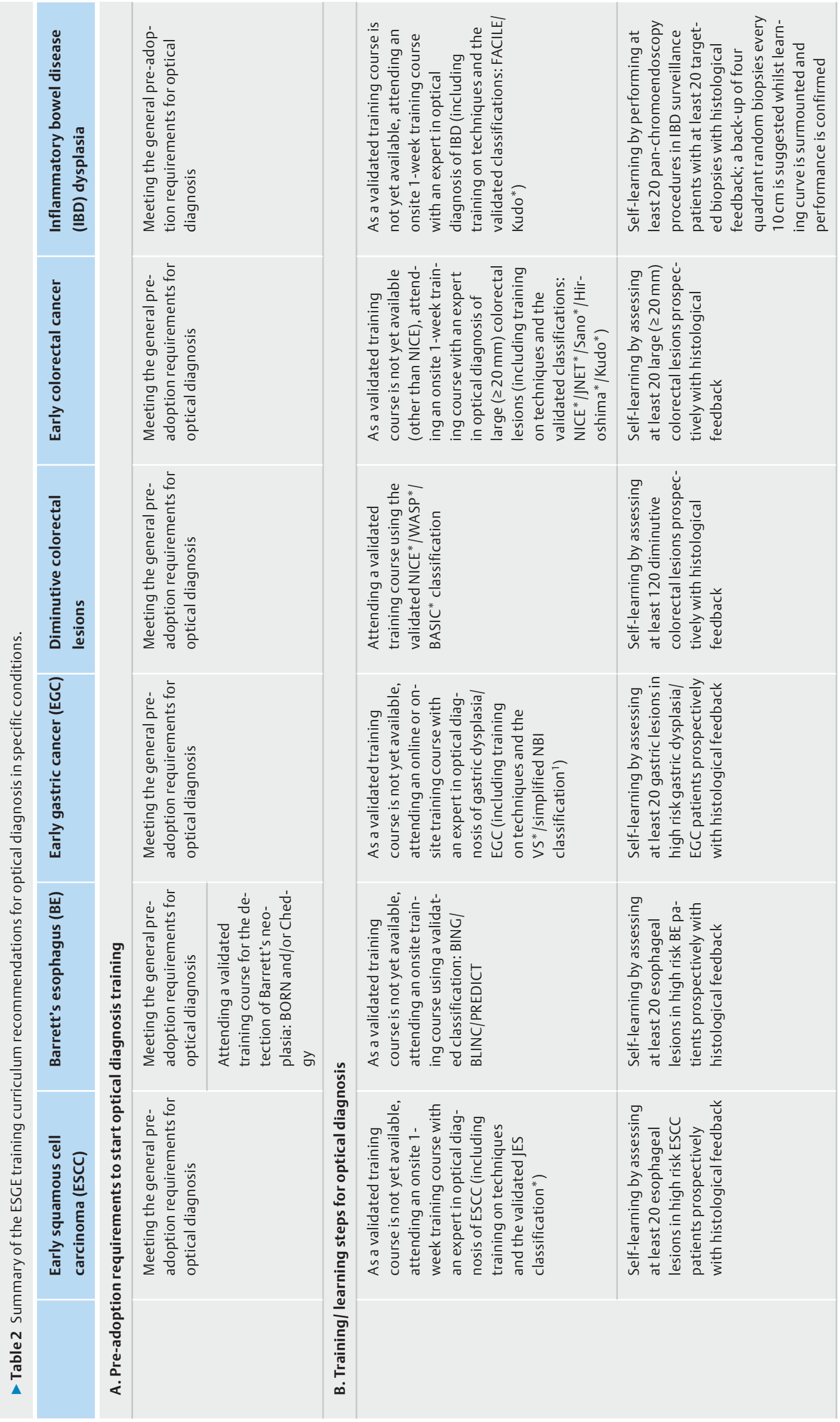




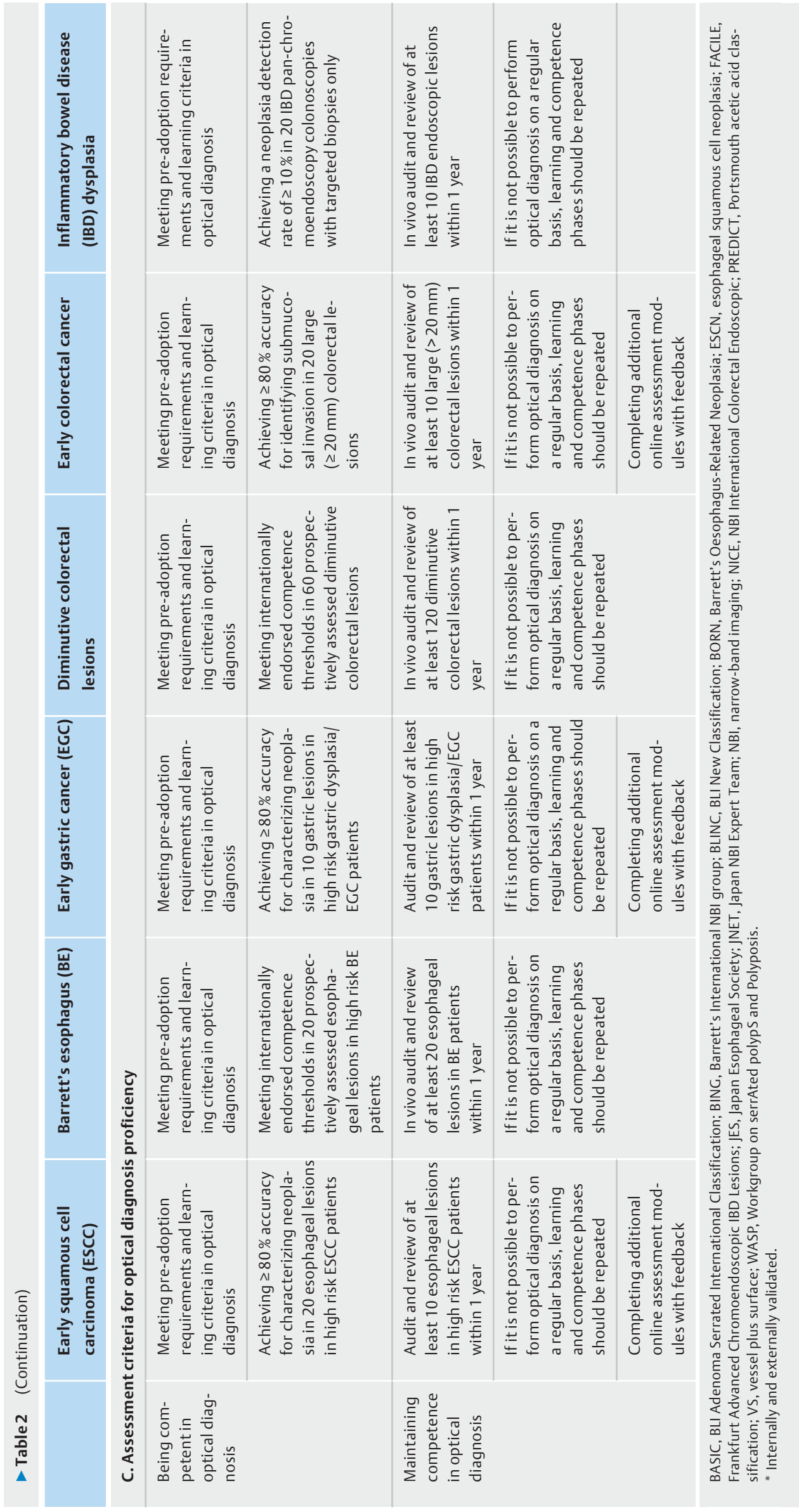


Three key areas of interest were decided upon for each main topic.

A. What are the pre-adoption requirements to start optical diagnosis training?

B. What are the training/learning steps to achieve competence in optical diagnosis?

C. What are the assessment criteria for optical diagnosis proficiency (being competent and maintaining competence)?

Different PICO questions (where P stands for population/patient, I for intervention/indicator, C for comparator/control, and $\mathrm{O}$ for outcome) were defined. An evidence-based Delphi process was used to develop consensus statements. The working group chairs (E.D. and J.E.) and B.H. worked with the other members of the working group (I.P., M.B., E.C., D.D., R.K., H.N.) to carry out a systematic collective search in the online Cochrane Library, Embase, and PubMed from 1990 to 1 March 2018, under the supervision of a medical librarian (Appendix 2s). Technologies considered for use for optical diagnosis were narrow-band imaging (NBI), linked color imaging ( $\mathrm{LCl}$ ), blue light imaging (BLI), blue laser imaging (BLI-laser), i-scan digital chromoendoscopy (i-scan), i-scan optical enhancement (i-scan $\mathrm{OE})$, conventional chromoendoscopy; white-light endoscopy (WLE), and Flexible spectral Imaging Color Enhancement (FICE; also known as Fujinon Intelligent Chromo Endoscopy).

For each statement, articles were individually assessed using the Grading of Recommendations Assessment, Development and Evaluation (GRADE) system for grading evidence levels and recommendation strengths [12]. The statements derived from the research questions of each key area of interest were adapted and/or excluded during iterative rounds of comments and suggestions from the working group members and former candidates during the Delphi process. Where evidence was limited or not available, expert opinions were derived and then refined based on the Delphi process. The evolution and adaptation of the clinical statements during the Delphi process was documented. A statement was accepted if at least $80 \%$ agreement was reached after at least three voting rounds. Sentences were voted on online by all optical diagnosis training group members, along with the ESGE curriculum group for endoscopic submucosal dissection (ESD) and the ESGE guideline group for advanced imaging for the detection and differentiation of colorectal neoplasia until a consensus was reached.

Because of the paucity of evidence, all statements should be considered GRADE weak, with low or very low quality evidence or expert opinion, with the exception of optical diagnosis for diminutive colorectal lesions [12].

\section{Optical diagnosis training in general}

\section{A. Pre-adoption requirements to start optical diagnosis training}

RECOMMENDATION

ESGE suggests that every endoscopist should have achieved general competence in upper gastrointestinal (UGI) endoscopy before commencing training in optical diagnosis of the UGI tract, meaning personal experience of at least $300 \mathrm{UGI}$ endoscopies and meeting the ESGE quality measures for UGI endoscopy. Level of agreement $89 \%$.

\section{RECOMMENDATION}

ESGE suggests that every endoscopist should have achieved general competence in lower gastrointestinal (LGI) endoscopy before commencing training in optical diagnosis of the LGI tract, meaning personal experience of at least $300 \mathrm{LGI}$ endoscopies and meeting the ESGE quality measures for LGI endoscopy.

Level of agreement $89 \%$.

Lesion assessment requires a stable position. This means avoiding loops, optimizing patient position, cleaning the lesion extensively, and managing the endoscope without the need of an assistant. Only if an endoscopist has mastered these standard technical skills, can mucosa and lesions be observed and diagnosed accurately. Sufficient technical proficiency in performing a standard gastrointestinal (GI) endoscopy, such as avoiding loops, should therefore be a prerequisite before commencing training in optical diagnosis [13].

The number of upper GI (UGI) and/or lower GI (LGI) endoscopies needed to achieve technical competence is uncertain and probably highly variable. It has been proposed that at least 200 LGI endoscopies should be performed during training to achieve competency in LGI endoscopy [14]. Past multicenter studies have shown that between 150 and 275 LGI endoscopies are required in order to consistently achieve a $90 \%$ success rate for cecal intubation [15-21]. However, much higher numbers perhaps as many as 450 cases - may be needed to be competent in lesion detection, and competency to this level with WLE should precede attempts to focus on optical diagnosis [22]. While data on the exact number of UGI endoscopies required to achieve competency in optical diagnosis of lesions of the UGI tract are scarce, a recent study showed that $>90 \%$ of trainees were able to achieve a $95 \%$ completion rate (i.e. passage of the endoscope to the duodenum without physical assistance) after performing 200 procedures [23]. Because optical diagnosis also requires correct positioning and stabilization of the endoscope, higher numbers may be needed for all endoscopists wishing to perform optical diagnosis of esophageal or gastric lesions. 
The ESGE and United European Gastroenterology have presented a short list of key performance measures for UGI and LGI endoscopy $[24,25]$. Because optical diagnosis also requires high quality endoscopy, in order to ensure basic competence in both UGI and LGI endoscopy, it is recommended that the same quality measures are adopted. For UGI endoscopy, a procedure time of $\geq 7$ minutes and inspection time of $\geq 1$ minute/ $\mathrm{cm}$ of the circumferential extent of the Barrett's epithelium are recommended. To assess performance measures, a total of 100 consecutive procedures should be used, or all procedures if $<100$ have been performed [24]. For LGI endoscopy, a cecal intubation rate $\geq 95 \%$, adenoma detection rate $\geq 25 \%$, and a minimum mean withdrawal time of 6 minutes [25-30] are recommended. In addition, validated competency assessment tools, such as the Direct Observation of Procedural Skills (DOPS) assessment tools developed by the Joint Advisory Group (JAG) on Gl endoscopy, can be used to assess technical proficiency $[31,32]$.

\section{RECOMMENDATION}

ESGE suggests that every endoscopist should be able and competent to perform UGI/LGI endoscopy with high definition white light combined with virtual and/or dye-based chromoendoscopy before commencing training in optical diagnosis.

Level of agreement $96 \%$.

The ESGE recently presented an update of the advanced imaging guideline for LGI endoscopy [33]. ESGE suggests that high definition endoscopy, and dye or virtual chromoendoscopy, as well as add-on devices, can be used in average risk patients to increase the endoscopist's adenoma detection rate. Because optical diagnosis also requires high quality equipment to ensure optimal endoscopist performance, it is recommended that endoscopists are able and competent to perform endoscopies with this equipment. In addition, the optimal equipment for the process of acquiring and storing images and/or video capture are mandatory for performing optical diagnosis. This equipment includes an appropriate video processor, a large high definition monitor, suitable cables for transporting the high definition digital signal, and high definition (video) capture to save the (video) images. When performing optical diagnosis to replace pathology diagnosis, clear unequivocal photo storage following national regulations is required.

\section{B. Training/learning steps for optical diagnosis}

\section{RECOMMENDATION}

ESGE suggests competency in optical diagnosis can be learned by: (1) attending a validated optical diagnosis training course; and (2) self-learning with a minimum number of lesions. If no validated training course is available, optical diagnosis can only be learned by attending a non-validated onsite training course and self-learning with a minimum number of lesions.

Level of agreement $89 \%$.

\section{RECOMMENDATION}

If available, ESGE suggests the use of optical diagnosis training courses that: (1) are based on a validated classification system; (2) have undergone internal and external validation; and (3) include an in vivo phase in which the endoscopists perform optical diagnosis during real-time endoscopy procedures.

Level of agreement $100 \%$.

Although it is possible to learn new skills through clinical experience, there is a risk that this will not cover the full breadth of pathology and potential mimics that may be encountered. Therefore, in line with other areas of medical training, formal training courses that ensure the full curriculum is covered are required as part of surmounting the learning curve to achieve full competence.

For optical diagnosis, many training courses have been developed. Most are linked to studies on the accuracy of optical diagnosis, others are promoted by companies. However, the vast majority of courses have not undergone internal and external validation, which should be the standard ( $\triangleright$ Table 3 ).

Internal validation is more or less a test for reproducibility. External validation with different lesions and different endoscopists is important to assess the robustness of the classification system and should also include assessment of face and content validation. "Face validity" is the extent to which a test is subjectively viewed as covering the concept it purports to measure, whereas "content validity" is the extent to which a test measures all facets of a given construct $[78,79]$.

Many optical diagnosis studies have assessed only ex vivo performance $[5-7,9,49,52,67,80-84]$. The main problem with optical diagnosis learning is the transition from evaluating still pictures to real-time endoscopy. Previous studies have suggested that training using still images and videos may not translate into high accuracy during real-time endoscopy [5, 8 , 85]. A standardized training course design should therefore ideally include an in vivo phase as well.

If no validated training course exists, a "learner" endoscopist should start to practice optical diagnosis in vivo after attending an onsite training course with an optical diagnosis expert. Selflearning with feedback from histology and occasionally from 
- Table 3 Different optical diagnosis classifications and training courses for each condition.

\begin{tabular}{|c|c|c|c|c|c|c|}
\hline Organ & Condition & $\begin{array}{l}\text { Classification } \\
\text { systems }\end{array}$ & Imaging technique & $\begin{array}{l}\text { Training } \\
\text { available (Yes/ } \\
\text { No) }\end{array}$ & $\begin{array}{l}\text { Training includes an } \\
\text { in vivo assessment } \\
\text { phase (Yes/No) }\end{array}$ & $\begin{array}{l}\text { Training exter- } \\
\text { nally validated } \\
\text { (Yes/No) }\end{array}$ \\
\hline \multirow[t]{6}{*}{ Esophagus } & \multirow{3}{*}{$\begin{array}{l}\text { Barrett's } \\
\text { esophagus }\end{array}$} & BING [34] & NBI near focus & No & No & No \\
\hline & & BLINC [35] & M-BLI & Yes [35] & No & No \\
\hline & & PREDICT [36] & $\mathrm{AA}-\mathrm{CE}$ & Yes [36] & No & No \\
\hline & \multirow{3}{*}{$\begin{array}{l}\text { Squamous } \\
\text { cell carcin- } \\
\text { oma }\end{array}$} & JES* [37-39] & M-NBI & Yes [40] & No & No \\
\hline & & Inoue [41-43] & $\mathrm{M}-\mathrm{NBI}$ & No & NA & NA \\
\hline & & Arima [44-46] & M-NBI & No & NA & NA \\
\hline \multirow[t]{2}{*}{ Stomach } & \multirow{2}{*}{$\begin{array}{l}\text { Early gastric } \\
\text { cancer }\end{array}$} & $\mathrm{VS}^{*}[47,48]$ & M-NBI/M-BLI & Yes $[49,50]$ & No & No \\
\hline & & NBI-simplified* [51] & NBI & Yes [52] & No & No \\
\hline \multirow[t]{13}{*}{ Colon etc. } & \multirow{6}{*}{$\begin{array}{l}\text { Diminutive } \\
\text { lesions }\end{array}$} & BASIC $* 53,54]$ & BLI & Yes $[53,54]$ & No & Yes [54] \\
\hline & & CONECCT [55] & NBI & Yes [55] & No & No \\
\hline & & ICE [56] & $\mathrm{OE}$ & Yes [56] & No & No \\
\hline & & $\operatorname{NICE}^{*}[57,58]$ & NBI & Yes $[59,58]$ & No & No \\
\hline & & SIMPLE [60] & $\mathrm{OE} / \mathrm{NBI}$ & Yes [60] & No & No \\
\hline & & WASP* [61] & NBI & Yes $[9,61]$ & Yes [9] & Yes [9] \\
\hline & \multirow[t]{5}{*}{ Early CRC } & NICE* $^{*}[57,62]$ & NBI & Yes $[58,59]$ & No & No \\
\hline & & Kudo $^{1}[63]$ & $\mathrm{M}-\mathrm{CE}$ & No & NA & NA \\
\hline & & Sano $^{1}[64-67]$ & M-NBI & No & NA & NA \\
\hline & & Hiroshima $[68-71]$ & M-NBI & No & NA & NA \\
\hline & & JNET' $[72-76]$ & M-NBI & No & NA & NA \\
\hline & \multirow[t]{2}{*}{$\begin{array}{l}\text { Neoplasia } \\
\text { IBD }\end{array}$} & FACILE [77] & $\begin{array}{l}\text { WLE, NBI, dye-based } \\
\text { CE, i-scan }\end{array}$ & No & NA & NA \\
\hline & & Kudo [63] & Dye-CE and NBI & No & NA & NA \\
\hline
\end{tabular}

the optical diagnosis expert (sending videos or pictures) will help to achieve competency. Although this period can take a long time, based on experience, we believe that assessing a minimum number of lesions prospectively is needed before competence should be assessed. Because there is no evidence available, the expert committee for this optical diagnosis training curriculum suggests that each subtopic should have a minimum caseload to learn optical diagnosis. Future studies should investigate these different caseloads in order to provide more evidence-based recommendations.

\section{RECOMMENDATION}

ESGE suggests that both classroom and online training courses can be used to improve the optical diagnosis accuracy of endoscopists.

Level of agreement $100 \%$.

No clear statement can be made on which type of training course is best. Different training course designs (classroom, self-directed web- or computer-based programs, etc.) have all shown efficacy for the initial steps of optical diagnosis learning [5-7, 9, 49, 52, 67, 80-84]. In two head-to-head comparisons, 
no difference in optical diagnosis performance was found between trainees randomized to online self-learning or didactic classroom teaching [86, 87]. In the study of Smith et al. [87], 16 trainees were randomized to receive online self-learning $(n=8)$ or didactic training $(n=8)$ using identical teaching materials and videos. No difference in diagnostic accuracy for the prediction of diminutive/small polyp histology was found between trainees who received didactic training and those who followed the computer-based program. Allen et al. [86] also found no difference in the accuracy of distinguishing adenomatous versus hyperplastic colon polyps between in-class teaching and online learning.

\section{RECOMMENDATION}

ESGE suggests that, for diseases with a low prevalence, online training should be considered a good alternative to onsite training to achieve and maintain competence. Level of agreement $93 \%$.

Because the incidence of EGC, ESCC, and early CRC during daily practice is very low, endoscopists should be exposed to more cases in a standardized training program, with the aim of obtaining a more extensive experience in optical diagnosis of these lesions [88]. In order to compensate for this lack of experience, a self-exercise online training course could be a good alternative for achieving and maintaining competence in optical diagnosis. Yao and colleagues developed an original self-exercise e-learning program, the so-called "100 cases for EGC detection training" [89]. During this online training course, the endoscopist predicts the diagnosis of 100 cases (50 cancer, 50 non-cancer) and receives feedback directly. Participants can repeat the training and mock tests as often as they wish until they feel sufficiently confident to perform optical diagnosis and draw clinical conclusions. We believe that similar repetitive online training courses could be a good alternative for low incidence optical diagnosis diseases.

The availability of adequate online teaching courses could enable widespread implementation of optical diagnosis in clinical practice. However, they are not a substitute to real-time endoscopy experience, which is the optimal method to develop excellence in optical diagnosis. The exposure to optical diagnosis of conditions with a low prevalence could also be increased by attending (expert) meetings to discuss cases from many endoscopists. During these meetings, the optical diagnosis and therapeutic plan can be discussed, and the histology results can be shown afterwards.

\section{Assessment criteria for optical diagnosis proficiency}

Being competent in optical diagnosis

\section{RECOMMENDATION}

ESGE suggests endoscopists are competent in optical diagnosis after: (1) meeting the pre-adoption and learning criteria; and (2) meeting competence thresholds by assessing a minimum number of lesions prospectively during real-time endoscopy.

Level of agreement $93 \%$.

People learn at different rates. For instance, studies during real colonoscopies have shown that, despite successfully completing a training course, some endoscopists never achieve a specific threshold $[5,9]$. Therefore, if endoscopists wish to perform optical diagnosis, they should demonstrate that the learning curve has been surmounted. The competence of endoscopists can be assessed by meeting competence thresholds in a minimum number of prospectively collected lesions during real-time endoscopy.

\section{RECOMMENDATION}

ESGE suggests objective and measurable parameters be implemented for assessing competence in optical diagnosis.

Level of agreement $100 \%$.

Currently, the only available benchmark for assessing competence are the PIVI criteria (Preservation and Incorporation of Valuable Endoscopic Innovations) [90,91]. Clear assessment of an objective and measurable parameter (externally reviewed) is necessary to demonstrate that the learning curve has been surmounted. Therefore, other objective and measurable parameters for assessing optical diagnosis competence should be developed. The working group of this optical diagnosis training curriculum have suggested a threshold to assess optical diagnosis competence for each subtopic. These thresholds should be examined to set more evidence-based recommendations. 


\section{Maintaining competence in optical diagnosis}

\section{RECOMMENDATION}

ESGE suggests ongoing in vivo practice by endoscopists to maintain competence in optical diagnosis. If a competent endoscopist does not perform in vivo optical diagnosis on a regular basis, ESGE suggests repeating the learning and competence phases to maintain competence. Level of agreement $89 \%$.

Competence is not static and may deteriorate over time, especially if a skill is rarely used. Mabe et al. [50] indicated that the learning effect might decrease if endoscopists do not continue their learning practice, but the required frequency of training is unclear. The recently published study of Bustamante-Balén et al. [92] shows that, following a non-practice period of 6 months, a drop in performance parameters occurs, and that it takes 150 lesions to get back to previous "expert" levels. Repetitive practice therefore seems crucial for maintaining competence. Thus, in order to remain competent in optical diagnosis, regular clinical application of this skill is required [6, 9, 93-95].

There is a scarcity of data on how many endoscopies or lesions evaluated with optical diagnosis are needed to maintain competence, partly because there is great variability in the learning speed between endoscopists [6,9] The only evidence comes from the study of Vleugels et al. [9]. This study showed that assessing 120 or more diminutive lesions in a period of 1 year was independently associated with more accurate histology prediction. Studies assessing how many lesions an endoscopist has to assess with optical diagnosis to maintain competence are lacking for the other optical diagnosis subtopics.

Although no evidence is available, the expert committee of this optical diagnosis training curriculum has suggested a minimum caseload within 1 year for each topic or that there should be repetition of the training/learning and competence phases in order to maintain proficiency in optical diagnosis. Ideally, these caseloads per year should be audited and reviewed during real-time endoscopies. Owing to the low prevalence of some optical diagnosis conditions, endoscopists may have limited opportunity to achieve the recommended number of cases, and therefore additional online training is suggested for maintaining competence in optical diagnosis.

Future studies should compare the outcomes of endoscopists with different caseloads in order to set a more evidence-based recommendation for a minimum volume of cases per year.

A logbook for optical diagnosis training is available for trainees on the ESGE website (https://www.esge.com/ optical-diagnosis-training-curriculum/).

\section{Optical diagnosis training for esophageal squamous cell cancer}

ESCC remains the most common type of esophageal cancer in the world [96]. Predicting the depth of infiltration is of pivotal importance when deciding on the appropriate treatment [37]. Because superficial mucosal lesions (stages $\mathrm{T} 1 \mathrm{~m} 1$ or $\mathrm{T} 1 \mathrm{~m} 2$ ) that are well to moderately differentiated and without lymphovascular invasion have a risk of lymph node metastases of less than $2 \%$, endoscopic resection is the preferred treatment option for these lesions. Recent data suggest the utility of optical diagnosis to guide clinical decisions in ESCC management, providing the Asian classifications can be easily learned and mastered by most endoscopists.

\section{A. Pre-adoption requirement to start optical diagnosis training}

There are no additional requirements over and above the general pre-adoption requirements to start optical diagnosis training for ESCC.

\section{B. Training/learning steps for optical diagnosis}

\section{RECOMMENDATION}

As a validated training course is not yet available for optical diagnosis of esophageal squamous cell carcinoma (ESCC), ESGE suggests attending an onsite training course using a validated classification of 1 week's duration with an expert in optical diagnosis of ESCC to achieve competence. To date the only validated classification is the Japan Esophageal Society (JES) classification.

Level of agreement $89 \%$.

\section{RECOMMENDATION}

In order to achieve competence in optical diagnosis of ESCC, ESGE suggests self-learning by assessing at least 20 esophageal lesions prospectively in high risk ESCC patients with histological feedback.

Level of agreement $93 \%$.

Lugol chromoendoscopy was recommended by the ESGE Quality Improvement Initiative for patients with an increased risk of ESCC [24]. However, the use of high definition endoscopes was not strictly recommended and the potential role of $\mathrm{NBI}$ was not mentioned. New data suggest that NBI or other virtual chromoendoscopy techniques, especially combined with magnification, might in expert hands replace Lugol chromoendoscopy to identify and characterize esophageal squamous cell neoplasia) [97].

Optical diagnosis for elevated (Paris 0-Is), slightly depressed (Paris 0-IIC), or ulcerated (Paris 0-III) esophageal lesions is not useful as these lesions are at very high risk of submucosal invasion and therefore are not candidates for endoscopic resection 
[98]. For flat lesions, intrapapillary capillary loop morphology visualized by NBI can help to predict the depth of invasion and choice for therapy. This is not feasible with Lugol chromoendoscopy. Classifications that help analyze intrapapillary capillary loop morphology, such as the Inoue classification and Arima classification, have seldom been used because of their relative complexity [41-46]. In 2017, the Japan Esophageal Society (JES) proposed a new simplified classification of four grades (A, $B 1, B 2$, and B3) based on the running pattern of microvessels or degree of dilation of severely irregular microvessels [37-39]. The JES classification has been externally validated in a retrospective multicenter Korean study performed in 69 patients from 2010 until 2016 [40]. The overall accuracy of magnifying NBI for estimating the depth of invasion of superficial ESCC was $79 \%$. These results support the use of the JES classification for ESCC, although few data are available on its use in the Western world.

The JES classification is helpful for predicting invasion depth, and thus guides the physician in deciding whether an endoscopic resection should be performed or not. Indeed, the following clinical decisions can be applied:

- non-neoplastic lesion $\rightarrow$ no resection

- intramucosal ESCC $\rightarrow$ appropriate for endoscopic mucosal resection (EMR) or ESD

- ESCC invading muscularis mucosae/SM1 $\rightarrow$ relative contraindication for endoscopic resection

- $\geq$ SM2 ESCC $\rightarrow$ formal contraindication for endoscopic resection.

Training courses with the validated JES classification are scarce. Recently, a Chinese study proposed a training course (1-hour video course) focusing on the JES classification [99]. The results of this study showed an improvement in accuracy for WLE combined with magnifying NBI versus WLE alone. Multivariate analyses revealed that the educational course, but not experience in endoscopy, $\mathrm{NBI}$, or magnification, significantly improved the diagnostic accuracy. Therefore, these results suggest a moderate, but potentially clinically relevant, benefit for such training courses. Where no validated training course exists, a "learner" endoscopist should start to use optical diagnosis in vivo after acquiring suitable knowledge from the literature and attending an onsite training course with an expert in optical diagnosis of ESCC. Self-learning with feedback from histology will help to achieve competence.

Studies assessing how many UGI endoscopies an endoscopist has to assess with optical diagnosis in patients with an increased risk for ESCC to achieve competence are lacking. Based on personal experience, the curriculum committee suggests assessment of at least 20 esophageal lesions prospectively in high risk ESCC patients.

\section{Assessment criteria for optical diagnosis proficiency}

Being competent in optical diagnosis

\section{RECOMMENDATION}

As a threshold is not available, ESGE suggests that an endoscopist is competent in optical diagnosis of ESCC after: (1) meeting the pre-adoption and learning criteria; and ( 2 ) achieving $\geq 80 \%$ accuracy in characterizing neoplasia in 20 esophageal lesions in high risk ESCC patients. Level of agreement $89 \%$.

No formal competence criteria for optical diagnosis in ESCC are available. In line with other criteria for competence in optical diagnosis where few data are available, the expert committee of this optical diagnosis training curriculum suggests, based on personal experience, an accuracy of $\geq 80 \%$ in characterizing neoplasia in 20 esophageal lesions in high risk ESCC patients.

\section{Maintaining competence in optical diagnosis}

\section{RECOMMENDATION}

ESGE suggests competence in optical diagnosis to predict ESCC can be maintained by audit and review of at least 10 esophageal lesions in high risk ESCC patients within 1 year. If it is not possible to perform optical diagnosis in high risk ESCC patients on a regular basis, the learning and competence phases should be repeated. Owing to the low prevalence of ESCC, ESGE suggests completing additional online assessment modules with feedback to maintain competence in optical diagnosis of ESCC. Level of agreement $93 \%$.

\section{Optical diagnosis training for Barrett's esophagus}

The detection of high grade dysplasia and esophageal adenocarcinoma with improved survival rates is the aim of optical diagnosis in BE. Advanced endoscopic imaging technologies improve the characterization of dysplastic BE by mucosal visualization and enhancement of the fine structural and microvascular details and may guide targeted biopsies for the detection of dysplasia during surveillance of patients with previously nondysplastic BE $[100,101]$. 


\section{A. Pre-adoption requirement to start optical diagnosis training}

\section{RECOMMENDATION}

ESGE suggests that endoscopists performing optical diagnosis in Barrett's esophagus (BE) patients should attend one of the following validated training courses for the detection of Barrett's neoplasia: (1) BORN training course for high definition white-light endoscopy; or (2) Chedgy training course for chromoendoscopy using acetic acid.

Level of agreement $96 \%$.

BE patients undergo regular endoscopic surveillance to detect curable lesions that are at high risk of developing into invasive esophageal adenocarcinoma. Detection is needed before characterization can begin. Training courses to improve early neoplasia detection are therefore an essential pre-adoption requirement for endoscopists optically diagnosing BE patients.

The only fully validated training course available is the "Barrett's Oesophagus-Related Neoplasia” (BORN) training course [102]. The results of the validation study demonstrate that general endoscopists with a wide range of experience and from different countries can substantially increase detection and delineation skills for early lesions (between baseline and the end of the trial, detection increased by $46 \%$, delineation increased by $129 \%$, agreement delineation increased by $105 \%$, and relative delineation increased by $106 \%[P<0.01])$. The condensed, final phase 2 BORN training module is now accredited for Continuing Medical Education and is available at no cost from www.iwgco.net, www.ueg.eu, or www.best-academia.eu.

Chedgy et al. developed a validated training tool for acetic acid chromoendoscopy-assisted lesion recognition in $\mathrm{BE}$ in 2018 [103]. The online training intervention significantly improved endoscopists' sensitivity to $95 \%$ from $83 \%$ at baseline and negative predictive value (NPV) to $94 \%$ from $83 \%$ at baseline. Further improvement was seen after a 1-day interactive seminar including live cases, with sensitivity increasing to $98 \%$ and NPV to $97 \%$.

\section{B. Training/learning steps for optical diagnosis}

\section{RECOMMENDATION}

As a validated training course is not yet available for optical diagnosis in BE, ESGE suggests attending an onsite training course using one of the following validated classifications for characterization of Barrett's epithelium:

(1) BING or (2) BLINC classifications for image-enhanced endoscopy (NBI, BLI); or (3) PREDICT classification for chromoendoscopy using acetic acid.

Level of agreement $89 \%$.

\section{RECOMMENDATION}

In order to achieve competence in optical diagnosis of BE, ESGE suggests self-learning by assessing at least 20 esophageal lesions prospectively in patients at high risk of BE with histological feedback.

Level of agreement $93 \%$.

For BE surveillance with $\mathrm{NBI}$ magnification, three different optical diagnosis classifications of mucosal and vascular pattern have been proposed: the Nottingham, Amsterdam, and Kansas classifications [104-107]. These three classifications have not been universally adopted because of their relative complexities and fair-to-moderate interobserver agreement.

More recently, the simpler Barrett's International NBI group (BING) classification for NBI with near-focus has been developed and validated by an international group of experts for the prediction of dysplastic BE, with $>90 \%$ accuracy and high interobserver agreement [34]. The validated classification system known as PREDICT (Portsmouth acetic acid classification), for the diagnosis of Barrett's neoplasia using acetic acid chromoendoscopy, demonstrates improvements in the sensitivity and NPV from $79 \%$ and $80 \%$ to $98 \%$ and $97 \%$, respectively ( $P<$ 0.001) [36]. Regarding BLI, Bhandari's group validated, in an image-based study, the BLINC classification (BLI New Classification) for the characterization of neoplastic and non-neoplastic $\mathrm{BE}$, based on color, pits, and vessels [35]. When BLINC was used by 10 expert endoscopists, the overall sensitivity, specificity, and accuracy of neoplasia identification were $96 \%, 94.4 \%$, and $95.2 \%$, respectively.

Currently, no training courses are available to improve optical diagnosis in BE. As no validated training course exists to improve optical diagnosis in BE, a "learner" endoscopist should start to use optical diagnosis in vivo after following the BORN and/or Chedgy training course for detection of BE and attending an onsite training course with an expert in optical diagnosis of BE. Although this learning period can take a long time, the expert committee suggests, based on personal experience, that assessment of at least 20 esophageal lesions prospectively in patients at high risk of $B E$ is needed before competence should be assessed. 


\section{Assessment criteria for optical diagnosis proficiency}

Being competent in optical diagnosis

\section{RECOMMENDATION}

ESGE suggests an endoscopist is competent in performing optical diagnosis of BE after attending a validated training course, which should include an in vivo phase, and reaching the internationally endorsed competence criteria during real-time UGI endoscopies.

Level of agreement $89 \%$.

\section{RECOMMENDATION}

ESGE suggests competence in optical diagnosis of BE can be evaluated by meeting the internationally endorsed competence criteria in 20 prospectively assessed esophageal lesions in high risk BE patients.

Level of agreement $93 \%$.

The American Society of Gastrointestinal Endoscopy (ASGE) Technology Committee performed a meta-analyses in which they established competence thresholds for surveillance of patients with non-dysplastic BE: (1) sensitivity of $\geq 90 \%$ and NPV of $\geq 98 \%$ for detecting high grade dysplasia or esophageal adenocarcinoma compared with the current standard protocol (WLE and targeted and random 4-quadrant biopsies every $2 \mathrm{~cm}$ ), and (2) specificity of $\geq 80 \%$ (compared with random biopsies) [101, 108]. These PIVI thresholds can be used to assess competence. Their meta-analysis indicated that targeted biopsies with acetic acid chromoendoscopy and virtual chromoendoscopy using NBI met the thresholds set by the ASGE PIVI criteria. Most of the studies evaluated in this meta-analysis were performed by experts in BE, which could be a potential limitation of the results. The use of NBI for optical diagnosis in BE surveillance was also supported by another meta-analysis with similar results: perpatient pooled sensitivity and specificity of $91 \%$ for detection of high grade dysplasia [109]. Regarding the dual focus system by Olympus, one study indicated an overall $86 \%$ reduction in the need for biopsies in high grade dysplasia [110].

The evidence for the use of acetic acid chromoendoscopy in the detection and characterization of Barrett's neoplasia is compelling. The large studies from the Portsmouth and Wiesbaden groups demonstrated that experts are able to meet the ASGE PIVI criteria $[111,112]$. The new BLI technology seems to have additional value for visualization of Barrett's neoplasia but up to now there are not enough data to support this [113,114].

Studies assessing how many esophageal lesions an endoscopist has to assess in high risk BE to evaluate optical diagnosis competence are lacking. Based on experience, it is suggested competence can be evaluated by assessing optical diagnosis performance in 20 prospectively detected esophageal lesions in high risk BE patients.

\section{Maintaining competence in optical diagnosis}

\section{RECOMMENDATION}

ESGE suggests competence in optical diagnosis of BE can be maintained by in vivo audit and review of at least 20 esophageal lesions in BE patients within 1 year. If it is not possible to perform optical diagnosis in $\mathrm{BE}$ on a regular basis, the learning and competence phases should be repeated.

Level of agreement $89 \%$.

\section{Optical diagnosis training for early gastric}

\section{cancer}

Gastric cancer is the one of the most common cancers with a significant mortality rate [88]. Early detection is key to improving the survival of gastric cancer patients [115]. UGI endoscopy is considered the best diagnostic procedure for early detection of gastric dysplasia and EGC. Advanced endoscopic imaging can improve mucosal visualization and endoscopic diagnosis of gastric dysplasia and cancer $[100,116]$; however, these advanced imaging techniques require additional training [117].

\section{A. Pre-adoption requirements to start optical diagnosis training}

There are no additional requirements over and above the general pre-adoption requirements to start optical diagnosis training for early gastric cancer (EGC).

\section{B. Training/learning steps for optical diagnosis}

\section{RECOMMENDATION}

ESGE suggests that endoscopists performing optical diagnosis in patients at high risk of gastric dysplasia/EGC should attend a training course using one of the following validated classifications: (1) the VS classification for virtual chromoendoscopy with magnification; (2) the simplified NBI classification for high definition NBI endoscopy. Level of agreement $85 \%$.

High definition chromoendoscopy improves the diagnosis of gastric precancerous conditions and early neoplastic lesions [118]. Whenever available, and after proper training, virtual chromoendoscopy, with or without magnification, should be used for the diagnosis of gastric precancerous conditions by guiding biopsies to stage atrophic and metaplastic changes and to target neoplastic lesions [118, 119].

Irregular vascular and/or surface patterns with the presence of a demarcation line are key criteria for the optical diagnosis of gastric neoplasia using virtual chromoendoscopy combined with magnification [120]. The "vessel plus surface" (VS) classification system is based on the ability of magnifying NBI or BLI 
to clearly visualize three categories of microvascular and microsurface patterns: regular, irregular, and absent $[47,48]$. Moreover, pattern irregularity identified using high definition NBI without magnification appears to be an accurate and reproducible feature for the diagnosis of gastric dysplasia and early cancer $[51,121]$. A simplified NBI classification for high definition $\mathrm{NBI}$ endoscopy was created by Pimentel-Nunes et al. [51].

\section{RECOMMENDATION}

As a validated training course is not yet available for optical diagnosis in gastric dysplasia/EGC, ESGE suggests attending an online and onsite training course using a validated classification of 1 week's duration with an expert in optical diagnosis of gastric dysplasia/EGC to achieve competence.

Level of agreement $93 \%$.

\section{RECOMMENDATION}

In order to achieve competence in optical diagnosis of gastric dysplasia/EGC, ESGE suggests self-learning by assessing at least 20 gastric lesions prospectively in patients at high risk gastric dysplasia/EGC with histological feedback.

Level of agreement $89 \%$.

In countries with a low prevalence of gastric cancer, endoscopists have limited opportunities to acquire sufficient optical diagnosis experience, and therefore onsite and additional online training is required. Currently no validated onsite training course based on a validated classification is available.

Multiple online training courses have however been developed. Two image-based studies demonstrated the efficacy of dedicated online training courses in improving practitioners' abilities to distinguish between gastric cancer and non-cancer using magnifying NBI with the validated VS classification [49, 50]. Another study with high definition NBI videos showed a $10 \%$ increase in global accuracy after an online training course on a simplified NBI classification [52]. After 200 videos, sensitivity and specificity of $80 \%$ and higher for intestinal metaplasia were observed in half the participants, with a specificity for dysplasia of greater than $95 \%$. Yao and colleagues developed an online training course to diagnose gastric cancer at an early stage using high definition WLE [89]. The study reported a significant improvement in EGC diagnosis for 166 doctors trained with the online course composed of video lectures about basic techniques and knowledge, and self-exercise tests with high definition endoscopic images of 100 cases [122]. The training module is available at no cost from www.higan-npo.com/elearning-endoscopy. A limitation of this large well-designed study is that the training was not based on a validated optical diagnosis classification system.
Studies assessing how many UGI endoscopies an endoscopist has to assess with optical diagnosis in patients at high risk for gastric dysplasia and cancer to achieve competence are lacking. The curriculum committee suggests, based on personal experience, that assessment of at least 20 gastric lesions prospectively in patients at high risk of gastric dysplasia/EGC is needed before competence should be assessed

\section{Assessment criteria for optical diagnosis proficiency}

Being competent in optical diagnosis

\section{RECOMMENDATION}

As a threshold is not available, ESGE suggests that an endoscopist is competent in optically diagnosing gastric dysplasia/EGC after: (1) meeting the pre-adoption and learning criteria; and (2) achieving $\geq 80 \%$ accuracy in characterizing neoplasia in 10 gastric lesions in high risk gastric dysplasia/EGC patients.

Level of agreement $93 \%$.

No formal competence criteria for optical diagnosis in gastric dysplasia/cancer are available; however, in line with other criteria for competence in optical diagnosis where no evidence is available, an expert opinion has been given. The expert committee of this optical diagnosis training curriculum suggests that an endoscopist is competent in optical diagnosis of EGC after meeting the pre-adoption and learning criteria and achieving $\geq 80 \%$ accuracy in characterizing neoplasia in 10 gastric lesions in high risk gastric dysplasia/cancer patients.

\section{Maintaining competence in optical diagnosis}

\section{RECOMMENDATION}

ESGE suggests competence in optical diagnosis of gastric dysplasia/EGC can be maintained by in vivo audit and review of at least 10 gastric lesions in high risk gastric dysplasia/EGC patients within 1 year. If it is not possible to perform optical diagnosis in high risk gastric dysplasia/ EGC patients on a regular basis, the learning and competence phases should be repeated. Owing to the low prevalence of gastric dysplasia/EGC, ESGE suggests completing additional online assessment modules with feedback to maintain competence in optical diagnosis of gastric dysplasia/EGC.

Level of agreement $89 \%$.

\section{Optical diagnosis training for diminutive colorectal lesions}

Real-time optical diagnosis of diminutive $(1-5 \mathrm{~mm})$ colorectal lesions during endoscopy could have important time and cost- 
saving potential [1-3]. This is the rationale for the "optical diagnosis strategy," in which diminutive polyps are resected and discarded without histopathological analysis, and non-neoplastic lesions in the rectosigmoid are left in place without resection, as they have no malignant potential.

As misdiagnosis of diminutive lesions can result in inappropriate surveillance intervals and neoplastic lesions being left in situ, endoscopists have to be sufficiently competent in performing optical diagnosis before implementing the optical diagnosis strategy. The learning process for diminutive polyp optical diagnosis may be a key point in achieving and maintaining a high performance level.

\section{A. Pre-adoption requirements to start optical diagnosis training}

There are no additional requirements over and above the general pre-adoption requirements to start optical diagnosis training for diminutive colorectal lesions.

\section{B. Training/learning steps for optical diagnosis}

\section{RECOMMENDATION}

ESGE recommends that endoscopists performing optical diagnosis of diminutive colorectal lesions should attend a validated training course using the externally validated NICE, WASP, and BASIC classifications. Other classifications could be incorporated into this recommendation provided that they have been fully validated.

Level of agreement $93 \%$.

Up to now, the NICE (NBI International Colorectal Endoscopic) classification, based on color, vessel, and surface pattern, and the WASP (Workgroup on serrAted polypS and Polyposis) classification, as an add-on for sessile serrated lesions, have been fully validated for $\mathrm{NBI}$ in clinical practice $[57,61$, 62]. Recently, the BASIC (BLI Adenoma Serrated International Classification) classification for BLI was externally validated in clinical practice $[53,54]$. Other proposed classifications, such as ICE (i-scan classification for endoscopic diagnosis using i-scan OE), SIMPLE (Simplified Identification Method for Polyp Labeling during Endoscopy for i-scan OE and NBI), and CONECCT (COlorectal Neoplasia Endoscopic Classification to Choose the Treatment), have not been fully validated $[55,56,60]$.

\section{RECOMMENDATION}

In order to achieve competence in optical diagnosis of diminutive colorectal lesions, ESGE suggests self-learning by assessing at least 120 diminutive colorectal lesions prospectively with histological feedback.

Level of agreement $93 \%$.
It is difficult to find evidence to support a specific number of cases to achieve competence. Studies evaluating the learning curve of endoscopists starting to use optical diagnosis demonstrate that learning has a huge individual variability [5, 9]. For instance, in the study of Ladabaum et al. [5], only $25 \%$ of the students met the PIVI competence criteria, one after evaluating 50 polyps and two after 120 polyps. In this article, the authors mention that 250 polyps are needed to achieve competence. A Spanish study demonstrated that, following a non-practice period of 6 months, a drop in performance parameters occurs, and that it takes 150 lesions to get back to previous "expert" levels [92].

\section{Assessment criteria for optical diagnosis proficiency}

Being competent in optical diagnosis

\section{RECOMMENDATION}

ESGE suggests an endoscopist is competent in performing optical diagnosis of diminutive colorectal lesions after attending a validated training course on the WASP, NICE, or BASIC classification, including an in vivo phase, and after reaching the internationally endorsed competence levels during real-time colonoscopies.

Level of agreement $89 \%$.

For optical diagnosis of diminutive polyps, the only fully validated training course with an in vivo assessment phase is the training based on the WASP classification [61]. However, this course is not yet publicly available. Other training courses have not yet been validated, are not based on a validated classification, or did not include an in vivo assessment phase during training ( $>$ Table 3 ).

\section{RECOMMENDATION}

ESGE suggests competence in optical diagnosis of diminutive colorectal lesions can be evaluated by meeting the internationally endorsed competence levels in at least 60 prospectively collected diminutive colorectal lesions. Level of agreement $93 \%$.

Currently, the PIVI criteria proposed by the ASGE are the standard benchmark to assess the competence of endoscopists in differentiating diminutive colorectal lesions [90,91]. For diminutive polyps, $\geq 90 \%$ agreement between surveillance intervals predicted by optical diagnosis and histology should be achieved. In addition, $\geq 90 \%$ NPV for diminutive neoplastic lesions in the rectosigmoid should be achieved. A weakness of the PIVI criteria on the agreement of surveillance intervals lies in the fact that the assessment is based on the combination of optical diagnosis of diminutive polyps and any larger polyps, if present. Therefore, mistakes in the optical diagnosis of diminu- 
tive polyps can be blurred by the effect of larger polyps when recommending the surveillance intervals. Moreover, concordance in surveillance intervals to some extent depends on the guideline used to set the intervals. Therefore, alternative benchmarking criteria should be developed [123]. In addition, the proportion of high confidence diagnoses should be recommended as a benchmark because only a substantial high rate of high confidence diagnoses would result in time and cost savings.

\section{Maintaining competence in optical diagnosis}

\section{RECOMMENDATION}

ESGE suggests competence in optical diagnosis of diminutive colorectal lesions can be maintained by in vivo audit and review of at least 120 diminutive lesions within 1 year. If it is not possible to optically diagnose diminutive lesions on a regular basis, the learning and competence phases should be repeated.

Level of agreement $85 \%$.

\section{Optical diagnosis training for early colorectal cancer}

As the prevalence of early CRC increases, optimization of optical diagnosis of early CRC is becoming more and more important to estimate the correct histology and choose the appropriate resection technique, with the ultimate aim of avoiding under- and overtreatment [124-128]. According to their clinical usefulness and current ability to predict histology, the main outcomes in optical diagnosis of early CRC are:

1. early CRC with deep submucosal invasion (SM2, 3, or $>1 \mathrm{~mm}$ ), because surgery is required as the risk of lymph node metastasis is increased five-fold $[129,130]$

2. high grade neoplasia / superficial early CRC (SM1 or < $1 \mathrm{~mm})$, because en bloc resection would be preferable to confirm that invasion is confined to the shallow submucosa or muscularis mucosae and to obtain free vertical and horizontal margins, and to accurately assess the risk factors for lymph node metastasis when there is submucosal invasion [131]

3. low grade neoplasia, because piecemeal EMR would be sufficient therapy.

\section{A. Pre-adoption requirements to start optical diagnosis training}

\section{RECOMMENDATION}

ESGE suggests that all endoscopists performing colonoscopy within bowel cancer screening programs, as well as those resecting lesions $\geq 20 \mathrm{~mm}$, should learn optical diagnosis for early colorectal cancer (CRC).

Level of agreement $96 \%$.
The implementation of bowel cancer screening programs has resulted in a growing number of diagnosed and early-treated (T1) CRCs worldwide [132-134]. Successful treatment of these colorectal lesions starts with the prediction of submucosal or deep submucosal invasion. A recent study performed in the Dutch national bowel cancer screening program showed that endoscopists optically diagnosed submucosal invasion in only $39 \%$ of 92 cases (95\% confidence interval [CI] 30\%-49\%) [128]. This limited accuracy for optical diagnosis of early CRC resulted in adjuvant surgical treatment in $11 \%$ of patients with lesions with submucosal invasion that were endoscopically correctly diagnosed and resected locally, compared with $41 \%$ of lesions with submucosal invasion that were endoscopically not recognized as cancer $(P=0.02)$. In another real-time Dutch study, which only included $\geq 20$-mm non-pedunculated lesions, a much higher sensitivity for optical diagnosis was reported, namely $79 \%$ (95\% Cl 64\%-89\%) [124]. However, the positive predictive value (PPV) in this study was rather low at $69 \%$ (95\% Cl 57\%-78\%), which might have resulted in unnecessary surgery. Hence, we can conclude that incorrect optical diagnosis when predicting submucosal and deep submucosal invasion results in suboptimal use of endoscopic and surgical treatment options [124-128].

Endoscopists performing colonoscopies on patients at high risk for early CRC (i. e. screening colonoscopy after fecal immunochemical test [FIT] or for the assessment of advanced therapeutic endoscopy techniques in large $(\geq 20 \mathrm{~mm})$ colorectal lesions) should therefore learn optical diagnosis for early CRC:

1. to safely perform piecemeal EMR in lesions with low grade neoplasia and low risk of submucosal invasion

2. to safely refer the patient to surgery because deep submucosal invasion is predicted

3. to be able to recognize polyps with uncertain diagnosis (which might be early CRC) in order to perform a diagnostic and possibly therapeutic en bloc resection if feasible, tattoo the site, and take special care of the specimen (preserve integrity and send it to the pathologist well-orientated) and, if an en bloc resection is not feasible (i. e. by EMR), to refer the patient for additional assessment by an experienced endoscopist to evaluate the mucosal pattern in detail (i.e. with magnification), to perform an advanced endoscopic en bloc resection (i. e. endoscopic full-thickness resection [eFTR], ESD), or to safely refer the patient to surgery

4. to be able to perform en bloc EMR instead of cold snare polypectomy to preserve the muscularis mucosae in small polyps with suspicion of high grade neoplasia or shallow submucosal invasion

5. to visualize and identify remnant polyp tissue that could have been left after EMR/piecemeal resection

6. to know when to bring the patient back for surveillance. 


\section{B. Training/learning steps for optical diagnosis}

\section{RECOMMENDATION}

ESGE suggests that endoscopists performing optical diagnosis on patients at high risk of early CRC should attend a validated training course using one of the following validated classifications: the NICE classification when no magnification is used; the JNET, Sano, Hiroshima, or Kudo classifications when magnification is used.

Level of agreement $92 \%$.

Two recent meta-analyses were performed to find out which characteristics are associated with the presence of early CRC and the prediction of deep submucosal invasion $[135,136]$. The sensitivity of the optical assessment improved particularly with the use of advanced imaging techniques such as chromoendoscopy or NBI. These techniques should therefore be an important part of the assessment of a polyp for the presence of early CRC. Nevertheless, morphological characteristics can make the endoscopist aware of an increased risk of malignancy and indicate how to investigate a polyp. Many optical diagnosis classification systems with different advanced imaging techniques have been developed to predict the risk of early CRC ( $\triangleright$ Table 3 and $\triangleright$ Table 4). Currently, there is insufficient evidence to express a preference for one specific classification.

Recently, Puig et al. [85] developed an easy decision rule to choose the most appropriate treatment when NBI without magnification is used: endoscopic treatment; refer for surgery; or refer for an accurate optical diagnosis with magnifying endoscopy or advanced procedure (i.e. ESD, eFTR) at an expert center. Based on this study, optical diagnosis using the validated NICE classification is useful firstly to rule out deep submucosal invasion in NICE type 1 and 2 lesions without nodules or depressed areas (NPV 99\%), and secondly to predict deep submucosal invasion when a non-pedunculated lesion (NICE type 3 ) is ulcerated (PPV 93\%) [85]. If an endoscopist detects a non-pedunculated NICE type 3 lesion without ulceration or a
NICE type 1 or 2 lesion with depressed areas or nodular-mixed type, the lesion should be assessed with magnifying virtual chromoendoscopy using the JNET, the Sano, or Hiroshima classification to perform an accurate optical diagnosis $[63,65,69-$ $73,135-139]$, because the prevalence of deep submucosal invasion is $44 \%, 10 \%$, and $9 \%$, respectively. Recent studies have suggested that the Kudo pit pattern with crystal violet should be assessed in JNET 2B (Sano IIIA) lesions, as they have been shown to include lesions with deep submucosal invasion too [74-76, 140 -143]. Finally, optical diagnosis for the prediction of deep submucosal invasion in pedunculated polyps is not useful and endoscopic treatment should be the first option [85, 144].

Two models for predicting deep submucosal invasion can help endoscopists in the endoscopic assessment of invasive carcinoma $[124,145]$. Based on these models, a select subgroup can be identified with an increased risk of invasive carcinoma. It is advised that endoscopists be aware of these prediction models. Although not validated in the model, the Hiroshima classification may be replaced by the JNET or the Sano classification.

\section{RECOMMENDATION}

As a validated training course is not yet available for optical diagnosis in early CRC (other than NICE), ESGE suggests attending an onsite training course using a validated classification of 1 week's duration with an expert in optical diagnosis of large ( $\geq 20 \mathrm{~mm}$ ) colorectal lesions to achieve competence.

Level of agreement $89 \%$.

\section{RECOMMENDATION}

In order to achieve competence in optical diagnosis of early CRC, ESGE suggests self-learning by assessing at least 20 large $(\geq 20 \mathrm{~mm})$ colorectal lesions prospectively with histological feedback.

Level of agreement $96 \%$.

- Table 4 Most likely pathology for predicting early colorectal cancer and for the prediction of deep submucosal invasion in non-pedunculated polyps according to different classifications systems.

\begin{tabular}{|c|c|c|c|c|c|}
\hline Classification system & $\begin{array}{l}\text { Hyperplastic polyp/ } \\
\text { sessile serrated lesion }\end{array}$ & $\begin{array}{l}\text { Low grade } \\
\text { adenoma }\end{array}$ & $\begin{array}{l}\text { High grade } \\
\text { adenoma }\end{array}$ & $\begin{array}{l}\text { Superficial submucosal } \\
\text { invasion }\end{array}$ & $\begin{array}{l}\text { Deep submucosal } \\
\text { invasion }\end{array}$ \\
\hline NICE $[57,62]$ & Type 1 & Type 2 & Type 2 & Type2 & Type 3 \\
\hline JNET [72 - 76] & Type 1 & Type 2A & Type 2B & Type 2B & Type 3 \\
\hline Sano [65] & I & II & IIIA & IIIA & IIIB \\
\hline Hiroshima $[69,70]$ & A & B & $\mathrm{C} 1$ & $\mathrm{C} 1 / \mathrm{C} 2$ & $\mathrm{C} 2 / \mathrm{C} 3$ \\
\hline Kudo [63] & $1 / 11$ & $\mathrm{III}_{\mathrm{L}} / \mathrm{II} \mathrm{I} / \mathrm{IV}$ & $\mathrm{Vi}$ & $\mathrm{Vi}$ & $\begin{array}{l}\mathrm{V}_{\mathrm{N}} / \mathrm{Vi}+\text { demarcated } \\
\text { area }\end{array}$ \\
\hline
\end{tabular}

NICE, NBI International Colorectal Endoscopic; JNET, Japan NBI Expert Team; III, III large tubular or roundish pits; III arrangement and sizes of $\mathrm{III}_{\mathrm{L}} / \mathrm{III}_{\mathrm{S}} / \mathrm{IV} ; \mathrm{V}_{\mathrm{N}}$, loss or decrease of pits with an amorphous structure. 
Unfortunately, dedicated and validated training courses on this subject are lacking. Published literature is scarce regarding the content of training on optical diagnosis of early CRC. A recent study showed that an easy-learning course of 20 minutes, using slides with examples, was enough to obtain high diagnostic accuracy values (area under the curve [AUC] 0.91, $95 \% \mathrm{Cl}$ $0.89-0.92$ ) in an image-based test with selected pictures, and to increase the number of lesions assessed with high confidence $(70.9 \%$ vs. $81.4 \%, P<0.001)$ [85]. However, the accuracy of the same endoscopists was much lower in real life (AUC 0.77 , $95 \% \mathrm{Cl} 0.72-0.83)$. Therefore, a real-time phase should be included in any training course.

As no validated training course exists, a "learner" endoscopist should start to use optical diagnosis in vivo after acquiring suitable knowledge from the literature (published papers and available atlas) and attending an onsite training course with an expert in optical diagnosis of large $(\geq 20 \mathrm{~mm})$ colorectal lesions [146]. Self-learning with feedback from histology and occasionally from the optical diagnosis expert (sending videos or pictures) will help to achieve competency. Although this period can take a long time (6-12 months), based on personal experience, the expert committee believes that the assessment of at least 20 large colorectal lesions prospectively is needed to learn optical diagnosis of early CRC.

\section{Assessment criteria for optical diagnosis proficiency}

\section{Being competent in optical diagnosis}

\section{RECOMMENDATION}

As a threshold is not available, ESGE suggests that an endoscopist is competent in optical diagnosis of early CRC after: (1) meeting the pre-adoption and learning criteria; and (2) achieving $\geq 80 \%$ accuracy for identifying submucosal invasion in 20 large $(\geq 20 \mathrm{~mm})$ colorectal lesions.

Level of agreement $85 \%$.

No specific requirement for accuracy threshold in clinical practice to assess optical diagnosis competence for early CRC is available. When defining a competence level for optical diagnosis of early CRC, it should be taken into consideration that incorrect optical diagnosis in lesions $<20 \mathrm{~mm}$ can lead to an unnecessary en bloc EMR and/or not placing a tattoo. However, incorrect optical diagnosis in lesions $\geq 20 \mathrm{~mm}$ can lead to inconclusive histology because piecemeal EMR is performed, an unnecessary ESD being performed when only low grade neoplasia is subsequently identified, or unnecessary surgery when the lesion is in fact benign. Although no evidence is available, the expert committee of this optical diagnosis training curriculum suggests that an endoscopist is competent in optically diagnosing early CRC after achieving $\geq 80 \%$ accuracy in identifying submucosal invasion in 20 large colorectal lesions.

\section{Maintaining competence in optical diagnosis}

\section{RECOMMENDATION}

ESGE suggests competence in optical diagnosis to predict early CRC can be maintained by in vivo audit and review of at least 10 large $(\geq 20 \mathrm{~mm})$ colorectal lesions within 1 year. If it is not possible to perform optical diagnosis in large colorectal lesions on a regular basis, the learning and competence phases should be repeated. Owing to the low prevalence of early CRC, ESGE suggests completing additional online assessment modules with feedback to maintain competence in optical diagnosis of early CRC. Level of agreement $89 \%$.

\section{Optical diagnosis training for inflammatory bowel disease}

Patients with IBD have an increased risk of developing colitisassociated cancer, which has been reported to be as high as $18 \%$ after 30 years of disease $[147,148]$. Surveillance colonoscopy with (virtual) chromoendoscopy is recommended in order to detect and treat the precursor lesions of cancer [149-152], because random biopsies are not effective for the detection of neoplasia $[150,153]$. Recommendations for training are lacking however.

\section{A. Pre-adoption requirements to start optical diagnosis training}

There are no additional requirements over and above the general pre-adoption requirements to start optical diagnosis training for neoplasia recognition in IBD (dye-based chromoendoscopy).

\section{B. Training/learning steps for optical diagnosis}

\section{RECOMMENDATION}

As a validated training course is not yet available for optical diagnosis of neoplasia in inflammatory bowel disease (IBD), ESGE suggests attending an onsite training course of 1 week's duration with an expert in optical diagnosis of IBD to achieve competence.

Level of agreement $85 \%$.

There is strong evidence that the use of dye-based chromoendoscopy for surveillance in IBD increases dysplasia detection $[149,150,152]$. The interpretation of chromoendoscopy findings in IBD is often challenging, resulting in prolonged procedure times and redundant biopsies. Accordingly, every endoscopist performing dye-based chromoendoscopy in IBD should undergo a dedicated training course to acquire the skills necessary for optical diagnosis of IBD-related lesions. Specific knowledge of the principles of both lesion detection and delineation should ideally be acquired under supervision by an expert in op- 
tical diagnosis of IBD, supported by atlases, videos, and webbased learning [154-156].

No optical diagnosis classification for IBD neoplasia has been fully validated. The classification commonly used to characterize visible lesions in IBD is the Kudo's classification [63]. Recent meta-analyses have suggested specific features (Kudo pit pattern type I or II, chromoendoscopy, or NBI) can be effective in enhancing the negative predictive value to $88 \%-94 \%$ [157, 158]. Subsequent data using high definition dye-based chromoendoscopy and endoscopic trimodal imaging support this $[159,160]$. An older study suggested a honeycomb-like or villous pattern was very unlikely to harbor dysplasia [161]. FICE using Kudo pit pattern also has acceptable diagnostic performance; however, it should be noted that Kudo pit pattern was not designed for use in IBD [162].

In 2019, the multimodal Frankfurt Advanced Chromoendoscopic IBD Lesions (FACILE) classification, based on visual characteristics, was proposed to identify colitis-associated neoplasia [77]. The results of multivariate analyses showed that the most relevant criteria for predicting dysplasia were flat (or non-polypoid) lesions, irregular surface and vessels, and signs of inflammation (AUC 0.76, 95\% Cl $0.73-0.78$ ). The classification was validated by assessing the diagnostic performance of experts and non-experts after completing an image-based training module. This classification deserves to be validated in vivo.

\section{RECOMMENDATION}

In order to achieve competence in optically diagnosing neoplasia in IBD, ESGE suggests self-learning by performing at least 20 pan-chromoendoscopy procedures in IBD surveillance patients with at least 20 targeted biopsies with histological feedback. During this phase, we suggest a back-up of four quadrant random biopsies every $10 \mathrm{~cm}$ whilst the learning curve is surmounted and performance is confirmed.

Level of agreement $92 \%$.

\section{RECOMMENDATION}

ESGE suggests that the transition from dye-based chromoendoscopy to virtual chromoendoscopy in IBD patients should be executed gradually.

Level of agreement $88 \%$.

Endoscopists performing optical diagnosis on IBD patients should be able and competent to perform colonoscopy with dye-based or virtual chromoendoscopy with targeted biopsies for neoplasia as this is regarded as the standard of care for neoplasia surveillance in IBD, following the recent update of the ESGE advanced imaging guideline [33]. Although the evidence on advanced imaging in the detection of colitis-associated neoplasia is sometimes contradictory, the additional value of dyebased chromoendoscopy seems acceptable [151,152]. Recent evidence with high definition endoscopes shows that virtual chromoendoscopy may be equivalent $[163,164]$.

Studies assessing how many IBD pan-chromoendoscopy or virtual chromoendoscopy procedures an endoscopist has to perform to achieve optical diagnosis competence are lacking. Based on experience and expert opinion, we suggest the progression of IBD chromoendoscopy training should be:

1. a dye-based chromoendoscopy training course of 1 week's duration with an expert in optical diagnosis

2. use of dye-based chromoendoscopy in at least 20 IBD surveillance patients with at least 20 biopsies targeted at suspicious lesions and normal-appearing mucosa with histological feedback; during this phase, we suggest a back-up of four quadrant random biopsies every $10 \mathrm{~cm}$ whilst the learning curve is surmounted and performance is confirmed

3. use of dye-based chromoendoscopy with targeted biopsies only, with histological feedback in 20 cases; random four quadrant biopsies can be abandoned

4. use of virtual chromoendoscopy in at least 20 IBD surveillance patients with at least 20 biopsies targeted at suspicious lesions and normal-appearing mucosa with histological feedback; during this phase, we suggest a back-up of four quadrant random biopsies every $10 \mathrm{~cm}$ whilst the learning curve is surmounted and performance is confirmed

5. use of virtual chromoendoscopy with targeted biopsies only with histological feedback in 20 cases; random four quadrant biopsies can be abandoned.

\section{Assessment criteria for optical diagnosis proficiency}

Being competent in optical diagnosis

\section{RECOMMENDATION}

As a threshold is not available, ESGE suggests that an endoscopist is competent in optically diagnosing neoplasia in IBD after: (1) meeting the pre-adoption and learning criteria; and (2) achieving a neoplasia detection rate of $\geq 10 \%$ in 20 IBD pan-chromoendoscopy colonoscopies with targeted biopsies only. Level of agreement $80 \%$.

No formal competence criteria for optical diagnosis of IBD dysplasia are available but, in line with other criteria for competence in optical diagnosis where few data are available, a combination of training and assessment was recommended by the expert committee. As neoplasia is found in $<15 \%$ of IBD cases using dye-spray in the community, the expert committee of this optical diagnosis training curriculum suggests a neoplasia detection rate of $\geq 10 \%$ in at least 20 pan-chromoendoscopy colonoscopies with targeted biopsies only should be achieved [158]. 


\section{Maintaining competence in optical diagnosis}

\section{RECOMMENDATION}

ESGE suggests competence in optically diagnosing neoplasia in IBD can be maintained by in vivo audit and review of at least $10 \mathrm{IBD}$ endoscopic lesions within 1 year. If it is not possible to perform optical diagnosis in IBD on a regular basis, the learning and competence phases should be repeated.

Level of agreement $89 \%$.

\section{Conclusions}

This ESGE Position Statement comprehensively addresses the major steps of optical diagnosis training. Optical diagnosis needs specific meticulous skills and dedicated training to achieve and maintain proficiency. The ability to perform a correct optical diagnosis allows us to provide optimal treatment for our patients.

The diverse topics covered in this curriculum include: the pre-adoption requirements prior to starting optical diagnosis training; the basic endoscopy skills, and the basic skills with advanced imaging techniques; the training/learning steps to achieve optical diagnosis competency; attendance at a validated optical diagnosis training course; and self-learning with a minimum number of lesions/cases with histopathology as the reference. As learning curves may be different from one trainee to another, this ESGE curriculum states assessment criteria to evaluate optical diagnosis proficiency; endoscopists are competent in optical diagnosis after meeting the pre-adoption and training/learning steps, and after meeting competence thresholds by assessing a minimum number of prospectively collected lesions during real-time endoscopy; endoscopists can maintain competency by ongoing practice with a minimum number of lesions/cases ( Table 1 and $>$ Table 2 ).

Throughout this ESGE curriculum, areas without evidence are highlighted, providing future research opportunities. We look forward to incorporating the results of these future studies into updates of this curriculum in the years to come.

\section{Disclaimer}

ESGE Position Statements represent a consensus of best practice based on the available evidence at the time of preparation. This is NOT a guideline but a proposal for training in optical diagnosis. The statements may not apply in all situations and should be interpreted in the light of specific clinical situations and resource availability. Further controlled clinical studies may be needed to clarify aspects of these statements, and revision may be necessary as new data appear. Clinical considerations may justify a course of action at variance with these recommendations. This ESGE Position Statement is intended to be an educational device to provide information that may assist endoscopists in providing care to patients. The recommendations are not rules and should not be construed as establishing a legal standard of care or as encouraging, advocating, requiring, or discouraging any particular treatment. The legal disclaimer for ESGE guidelines applies to the present position statement [10].

\section{Acknowledgment}

The authors gratefully thank the ESGE Curriculum group for ESD (Alana Ebigbo, Alba Panarese, Amyn Haji, Bas Weusten, Eduardo Albéniz, Frieder Berr, Mathieu Pioche, Pedro PimentelNunes, Pierre Deprez, and Pieter Dewint) and the ESGE Guideline group on advanced imaging for detection and differentiation of colorectal neoplasia (Cessare Hassan, George Cortas, Yark Hazewinkel, Maria Pellisé, Marietta lacucci, Michał F. Kaminski, and Serguei Mouzyka) for participating in the voting process and for their critical review of this Curriculum.

R. Bisschops is funded by the Research Foundation-Flanders. J. E. East was funded by the National Institute for Health Research (NIHR) Oxford Biomedical Research Centre. The views expressed are those of the author(s) and not necessarily those of the National Health Service, the NIHR, or the Department of Health.

\section{Competing interests}

M. Arvanitakis has received lecture fees from Olympus (2019-2020). $R$. Bisschops has received research support, speaker's and consultancy fees from Medtronic, Cook, Pentax, and Fujifilm (2009-2020), he has also received consultancy and speaker's fees from Norgine, Gl supply, Medivators, and Boston Scientific (2009-2020). E. Coron received speaker's fees or congress invitations from Fujifilm (20162019), and speaker's fees from Olympus (2016, 2017). E. Dekker received a research grant from Fujifilm, consulting fees for medical advice from Tillots (2018), Olympus (2019), Fujifilm (2017), GI Supply (2018 to present), and CPP-FAP (2019), and speaker's fees from Olympus (2018), Roche (2016, 2018), and GI Supply (2019); she has received equipment on loan from Fujifilm (2017 to present). M. DinisRibeiro received a research grant from Fujifilm (2019 to present) and a teaching grant from Olympus (2019 to present); he is also co-editor in-chief of Endoscopy. J. E. East is on the clinical advisory boards of Boston Scientific and Lumendi (2017-2019) and Satisfai Health and Paion (2020). G. Johnson has received speaker's fees from Boston Scientific (2012 to present) and has been a faculty member for annual training courses supported by Olympus, Pentax, and Boston Scientific (2012 to present). H. Neumann has provided consultancy to Fujifilm, SonoScape, Medtronic, and Boston Scientific (2019-2020). T. Ponchon has received research support from Olympus (2020). I. Puig has received speaker's fees from Fujifilm (2019) and his department has received loan equipment to conduct a study from Olympus Europe (2019-2021) and from Fujifilm Europe (2019). B.B.S.L. Houwen, D.E. Dobru, R. Kuvaev, P. Pimentel-Nunes, M. Bustamante-Balén, and D.S. Sanders declare that they have no conflict of interest.

References

[1] Hassan C, Pickhardt PJ, Kim DH et al. Systematic review: distribution of advanced neoplasia according to polyp size at screening colonoscopy. Aliment Pharmacol Ther 2010; 31: 210-217

[2] Kessler WR, Imperiale TF, Klein RW et al. A quantitative assessment of the risks and cost savings of forgoing histologic examination of diminutive polyps. Endoscopy 2011; 43: 683-691 
[3] Vleugels JLA, Greuter MJE, Hazewinkel Y et al. Implementation of an optical diagnosis strategy saves costs and does not impair clinical outcomes of a fecal immunochemical test-based colorectal cancer screening program. Endosc Int Open 2017; 5: E1197-E1207

[4] Kuiper T, Marsman WA, Jansen JM et al. Accuracy for optical diagnosis of small colorectal polyps in nonacademic settings. Clin Gastroenterol Hepatol 2012; 10: 1016-1020; quiz e1079

[5] Ladabaum U, Fioritto A, Mitani A et al. Real-time optical biopsy of colon polyps with narrow band imaging in community practice does not yet meet key thresholds for clinical decisions. Gastroenterology 2013; 144: 81-91

[6] Patel SG, Schoenfeld P, Kim HM et al. Real-time characterization of diminutive colorectal polyp histology using narrow-band imaging: implications for the resect and discard strategy. Gastroenterology 2016; 150: 406-418

[7] Rastogi A, Rao DS, Gupta N et al. Impact of a computer-based teaching module on characterization of diminutive colon polyps by using narrow-band imaging by non-experts in academic and community practice: a video-based study. Gastrointest Endosc 2014; 79: 390398

[8] Rees C], Rajasekhar PT, Wilson A et al. Narrow band imaging optical diagnosis of small colorectal polyps in routine clinical practice: the Detect Inspect Characterise Resect and Discard 2 (DISCARD 2) study. Gut 2017; 66: 887-895

[9] Vleugels JLA, Dijkgraaf MGW, Hazewinkel Y et al. Effects of training and feedback on accuracy of predicting rectosigmoid neoplastic lesions and selection of surveillance intervals by endoscopists performing optical diagnosis of diminutive polyps. Gastroenterology 2018; 154: 1682-1693.e1681

[10] Dumonceau JM, Hassan C, Riphaus A et al. European Society of Gastrointestinal Endoscopy (ESGE) Guideline Development Policy. Endoscopy 2012; 44: 626-629

[11] Bisschops R, Dekker E, East JE et al. European Society of Gastrointestinal Endoscopy (ESGE) curricula development for postgraduate training in advanced endoscopic procedures: rationale and methodology. Endoscopy 2019; 51: 976-979

[12] Guyatt GH, Oxman AD, Vist GE et al. GRADE: an emerging consensus on rating quality of evidence and strength of recommendations. BM] 2008; 336: 924-926

[13] Bronzwaer MES, Vleugels JLA, van Doorn SC et al. Are adenoma and serrated polyp detection rates correlated with endoscopists' sensitivity of optical diagnosis? Endoscopy 2020: doi:10.1055/a-11518691

[14] The Blue Book. The ESBGH Training Programme; 2017: Available from (Accessed: 10 July 2020): http://www.eubogh.org/blue-book/

[15] Lee S-H, Chung I-K, Kim S-J et al. An adequate level of training for technical competence in screening and diagnostic colonoscopy: a prospective multicenter evaluation of the learning curve. Gastrointest Endosc 2008; 67: 683-689

[16] Park H-J, Hong J-H, Kim H-S et al. Predictive factors affecting cecal intubation failure in colonoscopy trainees. BMC Med Educ 2013; 13: 5

[17] Sedlack RE. Training to competency in colonoscopy: assessing and defining competency standards. Gastrointest Endosc 2011; 74: 355366.e351-352

[18] Sedlack RE, Coyle W]. Assessment of competency in endoscopy: establishing and validating generalizable competency benchmarks for colonoscopy. Gastrointest Endosc 2016; 83: 516-523.e511

[19] Shahidi N, Ou G, Telford J et al. Establishing the learning curve for achieving competency in performing colonoscopy: a systematic review. Gastrointest Endosc 2014; 80: 410-416

[20] Siau K, Hodson J, Valori RM et al. Performance indicators in colonoscopy after certification for independent practice: outcomes and predictors of competence. Gastrointest Endosc 2019; 89: 482-492.e2
[21] Ward ST, Mohammed MA, Walt R et al. An analysis of the learning curve to achieve competency at colonoscopy using the JETS database. Gut 2014; 63: 1746-1754

[22] Munroe CA, Lee P, Copland A et al. A tandem colonoscopy study of adenoma miss rates during endoscopic training: a venture into uncharted territory. Gastrointest Endosc 2012; 75: 561-567

[23] Ward ST, Hancox A, Mohammed MA et al. The learning curve to achieve satisfactory completion rates in upper GI endoscopy: an analysis of a national training database. Gut 2017; 66: 1022-1033

[24] Bisschops R, Areia M, Coron E et al. Performance measures for upper gastrointestinal endoscopy: a European Society of Gastrointestinal Endoscopy (ESGE) Quality Improvement Initiative. Endoscopy 2016; 48: 843-864

[25] Kaminski MF, Thomas-Gibson S, Bugajski M et al. Performance measures for lower gastrointestinal endoscopy: a European Society of Gastrointestinal Endoscopy (ESGE) quality improvement initiative. United European Gastroenterol J 2017; 5: 309-334

[26] Barclay RL, Vicari J], Doughty AS et al. Colonoscopic withdrawal times and adenoma detection during screening colonoscopy. NEJM 2006; 355: 2533-2541

[27] Brenner H, Altenhofen L, Kretschmann J et al. Trends in adenoma detection rates during the first 10 years of the German screening colonoscopy program. Gastroenterology 2015; 149: 356-366.e351

[28] Calderwood AH, Schroy PC3rd et al. Boston Bowel Preparation Scale scores provide a standardized definition of adequate for describing bowel cleanliness. Gastrointest Endosc 2014; 80: 269-276

[29] Corley DA, Jensen CD, Marks AR et al. Adenoma detection rate and risk of colorectal cancer and death. NEJM 2014; 370: 1298-1306

[30] Shaukat A, Rector TS, Church TR et al. Longer withdrawal time is associated with a reduced incidence of interval cancer after screening colonoscopy. Gastroenterology 2015; 149: 952-957

[31] Siau K, Crossley J, Dunckley P et al. Direct observation of procedural skills (DOPS) assessment in diagnostic gastroscopy: nationwide evidence of validity and competency development during training. Surg Endosc 2020; 34: 105-114

[32] Siau K, Crossley J, Dunckley P et al. Colonoscopy Direct Observation of Procedural Skills assessment tool for evaluating competency development during training. Am J Gastroenterol 2020; 115: 234243

[33] Bisschops R, East JE, Hassan C et al. Advanced imaging for detection and differentiation of colorectal neoplasia: European Society of Gastrointestinal Endoscopy (ESGE) Guideline - Update 2019. Endoscopy 2019; 51: 1155-1179

[34] Sharma P, Bergman J], Goda K et al. Development and validation of a classification system to identify high-grade dysplasia and esophageal adenocarcinoma in Barrett's esophagus using narrow-band imaging. Gastroenterology 2016; 150: 591-598

[35] Subramaniam S, Kandiah K, Schoon E et al. Development and validation of the international blue-light imaging for Barrett's neoplasia classification. Gastrointest Endosc 2020; 91: 310-320

[36] Kandiah K, Chedgy FJQ, Subramaniam S et al. International development and validation of a classification system for the identification of Barrett's neoplasia using acetic acid chromoendoscopy: the Portsmouth acetic acid classification (PREDICT). Gut 2018; 67: 2085-2091

[37] Oyama $\mathrm{T}$, Inoue $\mathrm{H}$, Arima $\mathrm{M}$ et al. Prediction of the invasion depth of superficial squamous cell carcinoma based on microvessel morphology: magnifying endoscopic classification of the Japan Esophageal Society. Esophagus 2017; 14: 105-112

[38] Oyama T, Momma K, Makuuchi H. Japan esophageal society classification of superficial esophageal squamous cell carcinoma. Endosc Dig 2012; 24: 466-468

[39] Oyama T. A new classification of magnified endoscopy for superficial esophageal squamous cell carcinoma. Esophagus 2011; 8: 247-251 
[40] Kim S], Kim GH, Lee MW et al. New magnifying endoscopic classification for superficial esophageal squamous cell carcinoma. World J Gastroenterol 2017; 23: 4416

[41] Inoue H. Magnification endoscopy in the esophagus and stomach. Dig Endosc 2001; 13: S40-S41

[42] Inoue H, Honda T, Nagai K et al. Ultra-high magnification endoscopic observation of carcinoma in situ of the esophagus. Dig Endosc 1997; 9: $16-18$

[43] Inouhe H, Hondu T, Yoshida T et al. Ultra-high magnification endoscopy of the normal esophageal mucosa. Dig Endosc 1996; 8: 134-138

[44] Arima H. Magnified observation of esophageal mucosa. Gastroenterol Endosc 1998; 40: 1125-1137

[45] Arima M, Arima H, Tada M. Diagnosis of the invasion depth of early esophageal carcinoma using magnifying endoscopy with FICE. Stomach Intest 2010; 45: 1515-1525

[46] Arima M, Tada M, Arima H. Evaluation of microvascular patterns of superficial esophageal cancers by magnifying endoscopy. Esophagus 2005; 2: 191-197

[47] Yao K, Anagnostopoulos G, Ragunath K. Magnifying endoscopy for diagnosing and delineating early gastric cancer. Endoscopy 2009; 41: 462-467

[48] Yoshifuku Y, Sanomura Y, Oka S et al. Clinical usefulness of the VS classification system using magnifying endoscopy with blue laser imaging for early gastric cancer. Gastroenterol Res Pract 2017; 2017: 3649705

[49] Nakanishi H, Doyama $\mathrm{H}$, Ishikawa $\mathrm{H}$ et al. Evaluation of an e-learning system for diagnosis of gastric lesions using magnifying narrow-band imaging: a multicenter randomized controlled study. Endoscopy 2017; 49: 957-967

[50] Mabe K, Yao K, Nojima M et al. An educational intervention to improve the endoscopist's ability to correctly diagnose small gastric lesions using magnifying endoscopy with narrow-band imaging. Ann Gastroenterol 2014; 27: 149-155

[51] Pimentel-Nunes P, Dinis-Ribeiro M, Soares JB et al. A multicenter validation of an endoscopic classification with narrow band imaging for gastric precancerous and cancerous lesions. Endoscopy 2012; 44: 236-246

[52] Dias-Silva D, Pimentel-Nunes P, Magalhaes J et al. The learning curve for narrow-band imaging in the diagnosis of precancerous gastric lesions by using web-based video. Gastrointest Endosc 2014; 79: 910-920; quiz 983.e911-983.e914

[53] Bisschops R, Hassan C, Bhandari P et al. BASIC (BLI Adenoma Serrated International Classification) classification for colorectal polyp characterization with blue light imaging. Endoscopy 2018; 50: 211-220

[54] Rondonotti E, Hassan C, Andrealli A et al. Clinical validation of BASIC classification for the resect and discard strategy for diminutive colorectal polyps. Clin Gastroenterol Hepatol 2020: doi:10.1016/j. cgh.2019.12.028

[55] Fabritius M, Gonzalez JM, Becq A et al. A simplified table using validated diagnostic criteria is effective to improve characterization of colorectal polyps: the CONECCT teaching program. Endosc Int Open 2019; 7: E1197-E1206

[56] Bouwens MWE, de Ridder R, Masclee AAM et al. Optical diagnosis of colorectal polyps using high-definition i-scan: an educational experience. World J Gastroenterol 2013; 19: 4334-4343

[57] Hewett DG, Kaltenbach T, Sano Y et al. Validation of a simple classification system for endoscopic diagnosis of small colorectal polyps using narrow-band imaging. Gastroenterology 2012; 143: 599-607. e591

[58] Kaltenbach T, Rastogi A, Rouse RV et al. Real-time optical diagnosis for diminutive colorectal polyps using narrow-band imaging: the VALID randomised clinical trial. Gut 2015; 64: 1569-1577
[59] Ignjatovic A, Thomas-Gibson S, East JE et al. Development and validation of a training module on the use of narrow-band imaging in differentiation of small adenomas from hyperplastic colorectal polyps. Gastrointest Endosc 2011; 73: 128-133

[60] lacucci M, Trovato C, Daperno M et al. Development and validation of the SIMPLE endoscopic classification of diminutive and small colorectal polyps. Endoscopy 2018; 50: 779-789

[61] IJspeert JE, Bastiaansen BA, van Leerdam ME et al. Development and validation of the WASP classification system for optical diagnosis of adenomas, hyperplastic polyps and sessile serrated adenomas/ polyps. Gut 2016; 65: 963-970

[62] Hayashi N, Tanaka S, Hewett DG et al. Endoscopic prediction of deep submucosal invasive carcinoma: validation of the Narrow-Band Imaging International Colorectal Endoscopic (NICE) classification. Gastrointest Endosc 2013; 78: 625-632

[63] Kudo S, Tamura S, Nakajima T et al. Diagnosis of colorectal tumorous lesions by magnifying endoscopy. Gastrointest Endosc 1996; 44: $8-14$

[64] Sano Y, Horimatsu T, Fu Kl et al. Magnifying observation of microvascular architecture of colorectal lesions using a narrow-band imaging system. Dig Endosc 2006; 18: S44-S51

[65] Sano Y, Ikematsu H, Fu KI et al. Meshed capillary vessels by use of narrow-band imaging for differential diagnosis of small colorectal polyps. Gastrointest Endosc 2009; 69: 278-283

[66] Katagiri A, Fu KI, Sano Y et al. Narrow band imaging with magnifying colonoscopy as diagnostic tool for predicting histology of early colorectal neoplasia. Aliment Pharmacol Ther 2008; 27: 1269-1274

[67] Higashi R, Uraoka T, Kato ] et al. Diagnostic accuracy of narrow-band imaging and pit pattern analysis significantly improved for lessexperienced endoscopists after an expanded training program. Gastrointest Endosc 2010; 72: 127-135

[68] Tanaka S, Hirata M, Oka S et al. Clinical significance of narrow band imaging (NBI) in diagnosis and treatment of colorectal tumor. Gastroenterol Endosc 2008; 50: 1289-1297

[69] Kanao H, Tanaka S, Oka S et al. Narrow-band imaging magnification predicts the histology and invasion depth of colorectal tumors. Gastrointest Endosc 2009; 69: 631-636

[70] Oba S, Tanaka S, Oka S et al. Characterization of colorectal tumors using narrow-band imaging magnification: combined diagnosis with both pit pattern and microvessel features. Scand J Gastroenterol 2010; 45: 1084-1092

[71] Okamoto Y, Watanabe H, Tominaga K et al. Evaluation of microvessels in colorectal tumors by narrow band imaging magnification: including comparison with magnifying chromoendoscopy. Dig Dis Sci 2011; 56: $532-538$

[72] Sano Y, Tanaka S, Kudo SE et al. Narrow-band imaging (NBI) magnifying endoscopic classification of colorectal tumors proposed by the Japan NBI Expert Team. Dig Endosc 2016; 28: 526-533

[73] Iwatate M, Sano Y, Tanaka S et al. Validation study for development of the Japan NBI Expert Team classification of colorectal lesions. Dig Endosc 2018; 30: 642-651

[74] Minoda $\mathrm{Y}$, Ogino $\mathrm{H}$, Chinen $\mathrm{T}$ et al. Objective validity of the Japan Narrow-Band Imaging Expert Team classification system for the differential diagnosis of colorectal polyps. Dig Endosc 2019; 31: 544-551

[75] Sumimoto K, Tanaka S, Shigita K et al. Diagnostic performance of Japan NBI Expert Team classification for differentiation among noninvasive, superficially invasive, and deeply invasive colorectal neoplasia. Gastrointest Endosc 2017; 86: 700-709

[76] Sumimoto K, Tanaka S, Shigita K et al. Clinical impact and characteristics of the narrow-band imaging magnifying endoscopic classification of colorectal tumors proposed by the Japan NBI Expert Team. Gastrointest Endosc 2017; 85: 816-821 
[77] lacucci M, McQuaid K, Gui XS et al. A multimodal (FACILE) classification for optical diagnosis of inflammatory bowel disease associated neoplasia. Endoscopy 2019; 51: 133-141

[78] Lawshe CH. A quantitative approach to content validity 1. Pers Psychol 1975; 28: 563-575

[79] Wilson FR, Pan W, Schumsky DA. Recalculation of the critical values for Lawshe's content validity ratio. Meas Eval Couns Dev 2012; 45: 197-210

[80] Baldaque-Silva F, Marques M, Lunet $\mathrm{N}$ et al. Endoscopic assessment and grading of Barrett's esophagus using magnification endoscopy and narrow band imaging: impact of structured learning and experience on the accuracy of the Amsterdam classification system. Scand J Gastroenterol 2013; 48: 160-167

[81] Dai J, Shen YF, Sano Y et al. Evaluation of narrow-band imaging in the diagnosis of colorectal lesions: is a learning curve involved? Dig Endosc 2013; 25: 180-188

[82] Paggi S, Rondonotti E, Amato A et al. Resect and discard strategy in clinical practice: a prospective cohort study. Endoscopy 2012; 44: 899-904

[83] Patel SG, Rastogi A, Austin G et al. Gastroenterology trainees can easily learn histologic characterization of diminutive colorectal polyps with narrow band imaging. Clin Gastroenterol Hepatol 2013; 11: 997-1003.e1001

[84] Vu HT, Sayuk GS, Hollander TG et al. Resect and discard approach to colon polyps: real-world applicability among academic and community gastroenterologists. Dig Dis Sci 2015; 60: 502-508

[85] Puig I, Lopez-Ceron M, Arnau A et al. Accuracy of the narrow-band imaging international colorectal endoscopic classification system in identification of deep invasion in colorectal polyps. Gastroenterology 2019; 156: 75-87

[86] Allen JE, Vennalaganti P, Gupta $\mathrm{N}$ et al. Randomized controlled trial of self-directed versus in-classroom education of narrow band imaging in diagnosing colorectal polyps using the NICE criteria. J Clin Gastroenterol 2018; 52: 413-417

[87] Smith SC, Saltzman J, Shivaji UN et al. Randomized controlled study of the prediction of diminutive/small colorectal polyp histology using didactic versus computer-based self-learning module in gastroenterology trainees. Dig Endosc 2019; 31: 535-543

[88] Bray F, Ferlay J, Soerjomataram I et al. Global cancer statistics 2018: GLOBOCAN estimates of incidence and mortality worldwide for 36 cancers in 185 countries. CA Cancer J Clin 2018; 68: 394-424

[89] Yao K, Uedo N, Muto M et al. Development of an e-learning system for teaching endoscopists how to diagnose early gastric cancer: basic principles for improving early detection. Gastric Cancer 2017; 20: 28-38

[90] Abu Dayyeh BK, Thosani N, Konda V et al. ASGE Technology Committee systematic review and meta-analysis assessing the ASGE PIVI thresholds for adopting real-time endoscopic assessment of the histology of diminutive colorectal polyps. Gastrointest Endosc 2015; 81 : 502.e501-502.e516

[91] Rex DK, Kahi C, O'Brien M et al. The American Society for Gastrointestinal Endoscopy PIVI (Preservation and Incorporation of Valuable Endoscopic Innovations) on real-time endoscopic assessment of the histology of diminutive colorectal polyps. Gastrointest Endosc 2011; 73: 419-422

[92] Bustamante-Balen M, Satorres C, Puchades L et al. Non-guided selflearning program for high-proficiency optical diagnosis of diminutive and small colorectal lesions: A single-endoscopist pilot study. World J Gastroenterol 2019; 25: 1278-1288

[93] Branch WT Jr., Paranjape A. Feedback and reflection: teaching methods for clinical settings. Acad Med 2002; 77: 1185-1188

[94] Kaul P, Gong J, Guiton G. Effective feedback strategies for teaching in pediatric and adolescent gynecology. J Pediatr Adolesc Gynecol 2014; 27: $188-193$
[95] Richardson BK. Feedback. Acad Emerg Med 2004; 11: e1-e5

[96] Abnet CC, Arnold M, Wei W-QJG. Epidemiology of esophageal squamous cell carcinoma. Gastroenterology 2018; 154: 360-373

[97] Goda K, Dobashi A, Yoshimura N et al. Narrow-band imaging magnifying endoscopy versus Lugol chromoendoscopy with pink-color sign assessment in the diagnosis of superficial esophageal squamous neoplasms: a randomised noninferiority trial. Gastroenterol Res Pract 2015; 2015: 639462

[98] Zhuge L, Wang S, Xie J et al. A model based on endoscopic morphology of submucosal esophageal squamous cell carcinoma for determining risk of metastasis on lymph nodes. J Thorac Dis 2018; 10: 6846-6853

[99] Wang WL, Chiu SYH, Lee CT et al. A training program of a new simplified classification of magnified narrow band imaging for superficial esophageal squamous cell carcinoma. J Gastroenterol Hepatol 2018; 33: $1248-1255$

[100] East JE, Vleugels JL, Roelandt $P$ et al. Advanced endoscopic imaging: European Society of Gastrointestinal Endoscopy (ESGE) Technology Review. Endoscopy 2016; 48: 1029-1045

[101] Thosani N, Dayyeh BKA, Sharma P et al. ASGE Technology Committee systematic review and meta-analysis assessing the ASGE Preservation and Incorporation of Valuable Endoscopic Innovations thresholds for adopting real-time imaging-assisted endoscopic targeted biopsy during endoscopic surveillance of Barrett's esophagus. Gastrointest Endosc 2016; 83: 684-698.e687

[102] Bergman J, de Groof A, Pech O et al. An interactive web-based educational tool improves detection and delineation of Barrett's esophagus related neoplasia. Gastroenterology 2019; 156: 1299-1308.e3

[103] Chedgy F], Kandiah K, Barr H et al. Development and validation of a training module on the use of acetic acid for the detection of Barrett's neoplasia. Endoscopy 2017; 49: 121-129

[104] Sharma P, Bansal A, Mathur S et al. The utility of a novel narrow band imaging endoscopy system in patients with Barrett's esophagus. Gastrointest Endosc 2006; 64: 167-175

[105] Kara MA, Ennahachi M, Fockens P et al. Detection and classification of the mucosal and vascular patterns (mucosal morphology) in Barrett's esophagus by using narrow band imaging. Gastrointest Endosc 2006; 64: 155-166

[106] Singh R, Anagnostopoulos G, Yao K et al. Narrow-band imaging with magnification in Barrett's esophagus: validation of a simplified grading system of mucosal morphology patterns against histology. Endoscopy 2008; 40: 457-463

[107] Silva FB, Dinis-Ribeiro M, Vieth M et al. Endoscopic assessment and grading of Barrett's esophagus using magnification endoscopy and narrow-band imaging: accuracy and interobserver agreement of different classification systems (with videos). Gastrointest Endosc 2011; 73: 7-14

[108] Sharma P, Savides T], Canto MI et al. The American Society for Gastrointestinal Endoscopy PIVI (preservation and incorporation of valuable endoscopic innovations) on imaging in Barrett's esophagus. Gastrointest Endosc 2012; 76: 252-254

[109] Song J, Zhang J, Wang J et al. Meta-analysis of the effects of endoscopy with narrow band imaging in detecting dysplasia in Barrett's esophagus. Dis Esophagus 2015; 28: 560-566

[110] Singh R, Shahzad MA, Tam W et al. Preliminary feasibility study using a novel narrow-band imaging system with dual focus magnification capability in Barrett's esophagus: Is the time ripe to abandon random biopsies? Dig Endosc 2013; 25: 151-156

[111] Pohl J, Pech O, May A et al. Incidence of macroscopically occult neoplasias in Barrett's esophagus: are random biopsies dispensable in the era of advanced endoscopic imaging? Am J Gastroenterol 2010; 105: 2350 
[112] Tholoor S, Bhattacharyya R, Tsagkournis O et al. Acetic acid chromoendoscopy in Barrett's esophagus surveillance is superior to the standardized random biopsy protocol: results from a large cohort study (with video). Gastrointest Endosc 2014; 80: 417-424

[113] Kaneko K, Oono Y, Yano T et al. Effect of novel bright image enhanced endoscopy using blue laser imaging (BLI). Endosc Int Open 2014; 2: E212-E219

[114] Takeda T, Nagahara A, Ishizuka K et al. Improved visibility of Barrett's esophagus with linked color imaging: inter-and intra-rater reliability and quantitative analysis. Digestion 2018; 97: 183-194

[115] Leung WK, Wu MS, Kakugawa Y et al. Screening for gastric cancer in Asia: current evidence and practice. Lancet Oncol 2008; 9: 279-287

[116] Kuvaev RO, Kashin SV. The modern endoscopic investigation of the stomach with the application of the narrow-band imaging endoscopy and magnifying endoscopy: procedural techniques and diagnostic algorithms. Russ J Evid Based Gastroenterol 2016; 5: 3-12

[117] Sugano K, Tack J, Kuipers EJ et al. Kyoto global consensus report on Helicobacter pylori gastritis. Gut 2015; 64: 1353-1367

[118] Dinis-Ribeiro M, Areia M, de Vries AC et al. Management of precancerous conditions and lesions in the stomach (MAPS): guideline from the European Society of Gastrointestinal Endoscopy (ESGE), European Helicobacter Study Group (EHSG), European Society of Pathology (ESP), and the Sociedade Portuguesa de Endoscopia Digestiva (SPED). Endoscopy 2012; 44: 74-94

[119] Pimentel-Nunes P, Libanio D, Marcos-Pinto R et al. Management of epithelial precancerous conditions and lesions in the stomach (MAPS II): European Society of Gastrointestinal Endoscopy (ESGE), European Helicobacter and Microbiota Study Group (EHMSG), European Society of Pathology (ESP), and Sociedade Portuguesa de Endoscopia Digestiva (SPED) guideline update 2019. Endoscopy 2019; 51: 365-388

[120] Muto M, Yao K, Kaise M et al. Magnifying endoscopy simple diagnostic algorithm for early gastric cancer (MESDA-G). Dig Endosc 2016; 28: 379-393

[121] Pimentel-Nunes P, Libanio D, Lage J et al. A multicenter prospective study of the real-time use of narrow-band imaging in the diagnosis of premalignant gastric conditions and lesions. Endoscopy 2016; 48: 723-730

[122] Yao K, Uedo N, Muto M et al. Development of an e-learning system for the endoscopic diagnosis of early gastric cancer: an international multicenter randomized controlled trial. EBioMedicine 2016; 9: $140-147$

[123] Houwen B, Greuter M, Vleugels J et al. Sa1045 Guidance for setting alternative competence criteria for optical diagnosis of diminutive colorectal polyps, which are easier to implement in daily practice a simulation study. Gastrointest Endosc 2019; 89: AB152-AB153

[124] Backes Y, Schwartz MP, Ter Borg F et al. Multicentre prospective evaluation of real-time optical diagnosis of $\mathrm{T} 1$ colorectal cancer in large non-pedunculated colorectal polyps using narrow band imaging (the OPTICAL study). Gut 2019; 68: 271-279

[125] Bronzwaer MES, Koens L, Bemelman WA et al. Volume of surgery for benign colorectal polyps in the last 11 years. Gastrointest Endosc 2018; 87: 552-561.e551

[126] Hassan C, Repici A, Sharma P et al. Efficacy and safety of endoscopic resection of large colorectal polyps: a systematic review and metaanalysis. Gut 2016; 65: 806-820

[127] van Nimwegen LJ, Moons LMG, Geesing JM] et al. Extent of unnecessary surgery for benign rectal polyps in the Netherlands. Gastrointest Endosc 2018; 87: 562-570.e561

[128] Vleugels JLA, Koens L, Dijkgraaf MGW et al. Suboptimal endoscopic cancer recognition in colorectal lesions in a national bowel screening programme. Gut 2020; 69: 977-980

[129] Beaton C, Stephenson B, Williams G. Risk of lymph node metastasis in malignant colorectal polyps. Colorectal Dis 2014; 16: 67
[130] Bosch SL, Teerenstra S, de Wilt JH et al. Predicting lymph node metastasis in PT1 colorectal cancer: a systematic review of risk factors providing rationale for therapy decisions. Endoscopy 2013; 45: 827-841

[131] Nakadoi K, Tanaka S, Kanao H et al. Management of T1 colorectal carcinoma with special reference to criteria for curative endoscopic resection. J Gastroenterol Hepatol 2012; 27: 1057-1062

[132] Corley DA, Jensen CD, Quinn VP et al. Association between time to colonoscopy after a positive fecal test result and risk of colorectal cancer and cancer stage at diagnosis. JAMA 2017; 317: 1631-1641

[133] Schreuders EH, Ruco A, Rabeneck L et al. Colorectal cancer screening: a global overview of existing programmes. Gut 2015; 64: $1637-$ 1649

[134] van der Vlugt M, Grobbee EJ, Bossuyt PMM et al. Interval colorectal cancer incidence among subjects undergoing multiple rounds of fecal immunochemical testing. Gastroenterology 2017; 153: 439447.e432

[135] Backes Y, Moss A, Reitsma JB et al. Narrow band imaging, magnifying chromoendoscopy, and gross morphological features for the optical diagnosis of $\mathrm{T} 1$ colorectal cancer and deep submucosal invasion: a systematic review and meta-analysis. Am J Gastroenterol 2017; 112: 54-64

[136] Zhang QW, Teng LM, Zhang XT et al. Narrow-band imaging in the diagnosis of deep submucosal colorectal cancers: a systematic review and meta-analysis. Endoscopy 2017; 49: 564-580

[137] Ikematsu H, Matsuda T, Emura F et al. Efficacy of capillary pattern type IIIA/IIIB by magnifying narrow band imaging for estimating depth of invasion of early colorectal neoplasms. BMC Gastroenterol 2010; 10: 33

[138] Matsuda T, Fujii T, Saito Y et al. Efficacy of the invasive/non-invasive pattern by magnifying chromoendoscopy to estimate the depth of invasion of early colorectal neoplasms. Am J Gastroenterol 2008; 103: $2700-2706$

[139] Sano Y, Hirata D, Saito Y. Japan NBI Expert Team classification: Narrow-band imaging magnifying endoscopic classification of colorectal tumors. Dig Endosc 2018; 30: 543-545

[140] Sakamoto T, Matsuda T, Otake Y et al. Predictive factors of local recurrence after endoscopic piecemeal mucosal resection. J Gastroenterol 2012; 47: 635-640

[141] Lee B-I, Matsuda T. Estimation of invasion depth: the first key to successful colorectal ESD. Clin Endosc 2019; 52: 100

[142] Kobayashi S, Yamada M, Takamaru H et al. Diagnostic yield of the Japan NBI Expert Team (JNET) classification for endoscopic diagnosis of superficial colorectal neoplasms in a large-scale clinical practice database. United European Gastroenterol J 2019; 7: 914-923

[143] Komeda Y, Kashida H, Sakurai T et al. Magnifying narrow band imaging (NBI) for the diagnosis of localized colorectal lesions using the Japan NBI Expert Team (JNET) classification. Oncology 2017; 93 Suppl 1: 49-54

[144] Ikehara H, Saito Y, Matsuda T et al. Diagnosis of depth of invasion for early colorectal cancer using magnifying colonoscopy. J Gastroenterol Hepatol 2010; 25: 905-912

[145] Burgess NG, Hourigan LF, Zanati SA et al. Risk stratification for covert invasive cancer among patients referred for colonic endoscopic mucosal resection: a large multicenter cohort. Gastroenterology 2017; 153: 732-742.e731

[146] Muto M, Yao K, Sano Y. Atlas of Endoscopy with Narrow Band Imaging. Tokyo, Japan: Springer; 2015

[147] Jess T, Frisch M, Simonsen J. Trends in overall and cause-specific mortality among patients with inflammatory bowel disease from 1982 to 2010. Clin Gastroenterol Hepatol 2013; 11: 43-48 
[148] Jess T, Rungoe C, Peyrin-Biroulet L. Risk of colorectal cancer in patients with ulcerative colitis: a meta-analysis of population-based cohort studies. Clin Gastroenterol Hepatol 2012; 10: 639-645

[149] Bessissow T, Dulai PS, Restellini S et al. Comparison of endoscopic dysplasia detection techniques in patients with ulcerative colitis: a systematic review and network meta-analysis. Inflamm Bowel Dis 2018; 24: 2518-2526

[150] Bye WA, Ma C, Nguyen TM et al. Strategies for detecting colorectal cancer in patients with inflammatory bowel disease: a Cochrane systematic review and meta-analysis. Am J Gastroenterol 2018; 113: 1801-1809

[151] Kaltenbach TR, Soetikno RM, DeVivo R et al. Optimizing the quality of endoscopy in inflammatory bowel disease: focus on surveillance and management of colorectal dysplasia using interactive imageand video-based teaching. Gastrointest Endosc 2017; 86: 11071117.e1101

[152] Laine L, Kaltenbach T, Barkun A et al. SCENIC international consensus statement on surveillance and management of dysplasia in inflammatory bowel disease. Gastrointest Endosc 2015; 81: 489501.e426

[153] Vleugels JLA, Rutter MD, Ragunath K et al. Chromoendoscopy versus autofluorescence imaging for neoplasia detection in patients with longstanding ulcerative colitis (FIND-UC): an international, multicentre, randomised controlled trial. Lancet Gastroenterol Hepatol 2018; 3: 305-316

[154] Sanduleanu S, Rondagh EJ, Masclee AA. Development of expertise in the detection and classification of non-polypoid colorectal neoplasia: Experience-based data at an academic GI unit. Gastrointest Endosc Clin N Am 2010; 20: 449-460

[155] Leong RW, Butcher RO, Picco MF. Implementation of imageenhanced endoscopy into solo and group practices for dysplasia detection in Crohn's disease and ulcerative colitis. Gastrointest Endosc Clin N Am 2014; 24: 419-425
[156] Picco MF, Pasha S, Leighton JA et al. Procedure time and the determination of polypoid abnormalities with experience: implementation of a chromoendoscopy program for surveillance colonoscopy for ulcerative colitis. Inflamm Bowel Dis 2013; 19: 1913-1920

[157] Bisschops R, Bessissow T, Dekker E et al. Pit pattern analysis with high-definition chromoendoscopy and narrow-band imaging for optical diagnosis of dysplasia in patients with ulcerative colitis. Gastrointest Endosc 2017; 86: 1100-1106.e1101

[158] Carballal S, Maisterra S, Lopez-Serrano A et al. Real-life chromoendoscopy for neoplasia detection and characterisation in longstanding IBD. Gut 2018; 67: 70-78

[159] Lord R, Burr NE, Mohammed $\mathrm{N}$ et al. Colonic lesion characterization in inflammatory bowel disease: A systematic review and metaanalysis. World J Gastroenterol 2018; 24: 1167

[160] Vleugels JL, Rutter MD, Ragunath K et al. Diagnostic accuracy of endoscopic trimodal imaging and chromoendoscopy for lesion characterization in ulcerative colitis. J Crohns Colitis 2018; 12 : $1438-1447$

[161] Matsumoto T, Iwao Y, Igarashi M et al. Endoscopic and chromoendoscopic atlas featuring dysplastic lesions in surveillance colonoscopy for patients with long-standing ulcerative colitis. Inflamm Bowel Dis 2007; 14: 259-264

[162] Cassinotti A, Buffoli F, Fociani P et al. Virtual chromoendoscopy with FICE for the classification of polypoid and nonpolypoid raised lesions in ulcerative colitis. J Clin Gastroenterol 2019; 53: 269-276

[163] Bisschops R, Bessissow T, Joseph JA et al. Chromoendoscopy versus narrow band imaging in UC: a prospective randomised controlled trial. Gut 2018; 67: 1087-1094

[164] Har-Noy O, Katz L, Avni T et al. Chromoendoscopy, narrow-band imaging or white light endoscopy for neoplasia detection in inflammatory bowel diseases. Dig Dis Sci 2017; 62: 2982-2990

\section{CORRECTION}

Curriculum for optical diagnosis training in Europe: European Society of Gastrointestinal Endoscopy (ESGE) Position Statement

Dekker E, Houwen BBSL, Puig I et al.

Endoscopy 2020, 52: 899-923.

In the above-mentioned article, one sentence on page 912 (Optical diagnosis training for early gastric cancer, Part B) has been corrected. Correct is: The curriculum committee suggests, based on personal experience, that assessment of at least 20 gastric lesions prospectively in patients at high risk of gastric dysplasia/EGC is needed before competence should be assessed.

This was corrected in the online version on September 23, 2020. 